This document is the accepted manuscript version of the following article:

Vivanco, M. G., Bessagnet, B., Cuvelier, C., Theobald, M. R., Tsyro, S., Pirovano, G., ... Ung, A. (2017). Joint analysis of deposition fluxes and atmospheric concentrations of inorganic nitrogen and sulphur compounds predicted by six chemistry transport models in the frame of the EURODELTAIII project. Atmospheric Environment, 151, 152-175.

https://doi .org/10.1016/j. atmosenv.2016.11.042

This manuscript version is made available under the CC-BY-NC-ND 4.0 1icense

http: //creativecommons.org/1icenses/by-nc-nd/4.0/

\title{
1 Joint analysis of deposition fluxes and atmospheric \\ 2 concentrations of inorganic nitrogen and sulphur \\ 3 compounds predicted by six chemistry transport models in \\ 4 the frame of the EURODELTAIII project
}

5

6

M. G. Vivanco ${ }^{1}$, B. Bessagnet ${ }^{2,{ }^{\star}}$, C. Cuvelier $^{3}$, M. R. Theobald ${ }^{1}$, S.Tsyro ${ }^{4}$, G. Pirovano $^{5}$, A. Aulinger ${ }^{6}$, J. Bieser ${ }^{6}$, G. Calori ${ }^{7}$, G. Ciarelli ${ }^{8}$, A. Manders ${ }^{9}, \mathbf{M}$. Mircea $^{10}$, S. Aksoyoglu ${ }^{8}$, G. Briganti ${ }^{10}$, A. Cappelletti ${ }^{10}$, A. Colette ${ }^{2}$, F. Couvidat ${ }^{2}$, M. D'Isidoro ${ }^{10}$, R. Kranenburg ${ }^{9}$, F. Meleux ${ }^{2}$, L. Menut ${ }^{11}$, M.T. Pay ${ }^{12,}$, L. Rouï ${ }^{2}$, C. Silibello ${ }^{13}$, P. Thunis ${ }^{14}$, A. Ung ${ }^{2}$

[1]\{CIEMAT, Atmospheric Pollution Unit, Avda. Complutense, 22, 28040 Madrid, Spain \}

[2]\{INERIS, National Institute for Industrial Environment and Risks, Parc Technologique ALATA, F-60550 Verneuil-en-Halatte, France\}

[3] ex European Commission, Joint Research Centre (JRC), Ispra, Italy $\}$

[4]\{Climate Modelling and Air Pollution Division, Research and Development Department, Norwegian Meteorological Institute (MET Norway) P.O. Box 43, Blindern, N-0313 Oslo, Norway\}

[5]\{RSE S.p.A., via Rubattino 54, 20134 Milano, Italy

[6]\{HZG, Helmholtz-Zentrum Geesthacht, Institute for Coastal Research, Max-Planck-Straße 1, 21502 Geesthacht, Germany

[7]\{ARIANET Srl, Via Gilino n.9 20128, Milano, Italy

[8]\{PSI, Paul Scherrer Institute, 5232 Villigen, Switzerland $\}$

[9]\{TNO, Dept. Climate, Air and Sustainability, P.O. Box 80015, 3508 TA Utrecht, The Netherlands $\}$

[10]\{ENEA, Italian National Agency for New Technologies, Energy and Sustainable Economic Development (ENEA), Via Martiri di Monte Sole 4, 40129 Bologna, Italy 
1 [11] \{Ecole Polytechnique, 91128 Palaiseau, France $\}$

2 [12] \{BSC, Barcelona Supercomputing Center, Centro Nacional de Supercomputación, Nexus

3 II Building, Jordi Girona, 29, 08034 Barcelona, Spain \}

4 [13]\{ARIANET, via Gilino 9, 20128 Milano, ITALY\}

$5 \quad[14]\{$ European Commission, Joint Research Centre (JRC), Ispra, Italy\}

6 Correspondence to: M. G. Vivanco (m.garcia@ ciemat.es)

7 Abstract

8 In the framework of the UNECE Task Force on Measurement and Modelling (TFMM) under the Convention on

9 Long-range Transboundary Air Pollution (LRTAP), the EURODELTAIII project is evaluating how well air 10 quality models are able to reproduce observed pollutant air concentrations and deposition fluxes in Europe. In this paper the sulphur and nitrogen deposition estimates of six state-of-the-art regional models (CAMx, CHIMERE, EMEP MSC-W, LOTOS-EUROS, MINNI and CMAQ) are evaluated and compared for four intensive EMEP measurement periods (25 Feb - 26 Mar 2009; 17 Sep - 15 Oct 2008; 8 Jan - 4 Feb 2007 and 1 30 Jun 2006).

For sulphur, this study shows the importance of including sea salt sulphate emissions for obtaining better model results; CMAQ, the only model considering these emissions in its formulation, was the only model able to reproduce the high measured values of wet deposition of sulphur at coastal sites. MINNI and LOTOS-EUROS underestimate sulphate wet deposition for all periods and have low wet deposition efficiency for sulphur.

For reduced nitrogen, all the models underestimate both wet deposition and total air concentrations (ammonia plus ammonium) in the summer campaign, highlighting a potential lack of emissions (or incoming fluxes) in this period. In the rest of campaigns there is a general underestimation of wet deposition by all models (MINNI and CMAQ with the highest negative bias), with the exception of EMEP, which underestimates the least and even overestimates deposition in two campaigns. This model has higher scavenging deposition efficiency for the aerosol component, which seems to partly explain the different behaviour of the models.

For oxidized nitrogen, CMAQ, CAMx and MINNI predict the lowest wet deposition and the highest total air concentrations (nitric acid plus nitrates). Comparison with observations indicates a general underestimation of wet oxidized nitrogen deposition by these models, as well as an overestimation of total air concentration for all the campaigns, except for the 2006 campaign. This points to a low efficiency in the wet deposition of oxidized nitrogen for these models, especially with regards to the scavenging of nitric acid, which is the main driver of oxidized $\mathrm{N}$ deposition for all the models. CHIMERE, LOTOS-EUROS and EMEP agree better with the observations for both wet deposition and air concentration of oxidized nitrogen, although CHIMERE seems to overestimate wet deposition in the summer period. This requires further investigation, as the gas-particle equilibrium seems to be biased towards the gas phase (nitric acid) for this model.

In the case of MINNI, the frequent underestimation of wet deposition combined with an overestimation of atmospheric concentrations for the three pollutants indicates a low efficiency of the wet deposition processes. This can be due to several reasons, such as an underestimation of scavenging ratios, large vertical concentration gradients (resulting in small concentrations at cloud height) or a poor parameterization of clouds.

Large differences between models were also found for the estimates of dry deposition. However, the lack of suitable measurements makes it impossible to assess model performance for this process. These uncertainties should be addressed in future research, since dry deposition contributes significantly to the total deposition for the three deposited species, with values in the same range as wet deposition for most of the models, and with even higher values for some of them, especially for reduced nitrogen. 


\section{Introduction}

2 Atmospheric deposition of air pollutants can lead to a range of detrimental impacts to

3 terrestrial and aquatic ecosystems. Nitrogen $(\mathrm{N})$ deposition is currently considered a major

4 threat to European biodiversity, including sensitive habitats and species listed under the

5 European Commission Habitats Directive (92/43/EEC) (Sutton et al., 2011; Ochoa et al.,

6 2014). $\mathrm{N}$ deposition can lead to the replacement of local plant communities of species adapted

7 to low-nutrient environments by nitrophilous species able to thrive under high-N conditions

8 (Stevens et al., 2004). On the other hand, an alteration of soil $\mathrm{N}$ and carbon storage could

9 contribute to either mitigate or reinforce the effects of climate change (Reich et al., 2006).

10 The deposition of both sulphur ( $\mathrm{S}$ ) and nitrogen $(\mathrm{N})$ can lead to the acidification of soils as

11 well as freshwater and marine ecosystems (Longhurst, 1991). Acidification makes forests and

12 other ecosystems more vulnerable to stress factors such as frost, drought and pests (Bouwman

13 et al., 2002, Heij and Schneider, 1991).

14 It is generally difficult and expensive to measure the components of atmospheric deposition, 15 especially dry deposition fluxes, and thus the use of deposition estimates simulated by 16 chemical transport models (CTMs) has become a common practice. Nowadays modelled 17 deposition is commonly used to evaluate a range of environmental impacts. For example, modelled deposition fluxes of nitrogen and sulphur can be used to evaluate potential ecosystem damage by comparing annual deposition rates with habitat-specific thresholds, such as critical loads for acidification and nutrient nitrogen (Nilsson et al., 1988). Maps of the exceedances of critical loads in Europe for last decades can be found in annual EMEP Status Reports (http:// www.emep.int). A robust evaluation of model capabilities to correctly predict atmospheric deposition rates is, therefore, necessary, beyond the evident importance of correctly calculating air pollutant concentrations.

Atmospheric deposition can occur through dry or wet mechanisms. Wet deposition refers to the processes of scavenging of air pollutant by hydrometeors, i.e. cloud and fog droplets, rain or solid precipitation. One of these processes is the dissolution into cloud-drops of soluble gases such as $\mathrm{NH}_{3}, \mathrm{HNO}_{3}$ and $\mathrm{SO}_{2}$, present in the interstitial cloud air. A proportion of aerosol particles (nitrates, sulphates) can also be removed within clouds by incorporation into the liquid phase. Below clouds, pollutants can be scavenged by precipitation elements between 
1 the cloud base and the surface. Soluble gas species can dissolve into falling raindrops during

2 rain, while airborne particles can be collected by raindrops through collisions. Dry deposition

3 includes a downward transport and the subsequent uptake of the atmospheric pollutant species

4 by surfaces, in the absence of precipitation. Models generally use an approach based on an

5 electrical resistance analogy, defining a "resistance" to deposition, for the turbulent transport,

6 molecular diffusion and surface processes, adding them in the same way as electrical

7 resistances. Downward fluxes for particles can also be increased by sedimentation.

8 The presence of $\mathrm{NH}_{3}, \mathrm{HNO}_{3}$ and $\mathrm{H}_{2} \mathrm{SO}_{4}$ in the atmosphere is the result of a combination of

9 processes. Whereas ammonia is directly emitted, nitric acid $\left(\mathrm{HNO}_{3}\right)$ and sulphuric acid

$10 \quad\left(\mathrm{H}_{2} \mathrm{SO}_{4}\right)$ can be formed through the oxidation of nitrogen dioxide $\left(\mathrm{NO}_{2}\right)$ and sulphur dioxide

$11\left(\mathrm{SO}_{2 .}\right)$. Anthropogenic $\mathrm{SO}_{2}$ emissions mainly come from the combustion of fossil fuels

12 (primarily coal and oil), whereas natural sources of atmospheric $\mathrm{S}$ include volcanoes and

13 marine algae, mainly in the form of dimethyl sulphide (DMS). Nitric oxide (NO) and $\mathrm{NO}_{2}$

14 emissions are mainly from fossil fuel combustion, biomass burning, and microbiological

15 emissions from soils (Lee et al., 1997). In Europe $\mathrm{NH}_{3}$ mostly comes from agricultural

16 practices such as the volatilization from animal waste and synthetic fertilizers with

17 contributions from other sources such as biomass burning, emissions from oceans and soils

18 under natural vegetation, emissions from waste industrial processes and transport (Bouwman

19 et al., 1997). Ammonia is the only significant alkaline gas of significance in the atmosphere,

20 playing an important role in neutralizing acids. Sulphates, nitrates and ammonium can be

21 formed when $\mathrm{H}_{2} \mathrm{SO}_{4}$ and $\mathrm{HNO}_{3}$ are neutralized by $\mathrm{NH}_{3}$, forming ammonium sulphate

$22\left(\mathrm{NH}_{4}\right)_{2} \mathrm{SO}_{4}$ and bisulphate $\left(\mathrm{NH}_{4}\right) \mathrm{HSO}_{4}$, in the case of $\mathrm{H}_{2} \mathrm{SO}_{4}$, and ammonium nitrate

$23\left(\mathrm{NH}_{4} \mathrm{NO}_{3}\right)$ in the case of $\mathrm{HNO}_{3}$. The formation of ammonium sulphate is the favoured

24 reaction; i.e. nitrates are only formed once all sulphate is neutralized by $\mathrm{NH}_{3}$. As ammonium

25 nitrate can evaporate easily, the formation of nitrates is a reversible process, with the

26 formation reaction favoured by low temperatures and high relative humidity.

27 CTMs include chemical mechanisms describing the atmospheric gas-phase chemistry, based 28 on various reaction schemes (e.g. CB05, MELCHIOR, SAPRC99, etc.). The way these 29 mechanisms parameterise the oxidation chemistry (i.e. $\mathrm{NO}$ reacting to form $\mathrm{NO}_{2}$, which then 30 goes on to form $\mathrm{HNO}_{3}, \mathrm{SO}_{2}$ forming $\mathrm{H}_{2} \mathrm{SO}_{4}$ via oxidation of $\mathrm{OH}$ or other reactions affecting $31 \mathrm{NO}_{2}, \mathrm{SO}_{2}$ and other oxidant concentrations) has an effect on the formation of $\mathrm{HNO}_{3}$ and $32 \mathrm{H}_{2} \mathrm{SO}_{4}$. Once the concentrations of the gaseous aerosol precursors are calculated, the next step 
1 in the models is to simulate their condensation onto the aerosol phase and to estimate the

2 concentrations of aerosol species (nitrates, sulphates and ammonium, among others). In

3 general, CTMs assume that the atmospheric gases and inorganic species (aqueous ions or

4 precipitated solids) are in thermodynamical equilibrium, using aerosol inorganic equilibrium

5 models such as ISORROPIA (Nenes et al., 1998) or MARS (Binkowski and Shankar, 1995)

6 models.

7 While a large number of studies have focused on the evaluation of air pollutant concentration

8 predictions in Europe, far fewer have looked at the deposition of nitrate, ammonium and

9 sulphate. Estimates of total nitrogen deposition cannot be directly evaluated because of a lack

10 of measurements, especially of dry nitrogen deposition. For gaseous nitrogen species,

11 estimates of dry deposition are usually based on measurements of concentrations combined

12 with estimates of the deposition velocity (Flechard et al., 2011). On the other hand, Simpson

13 et al. (2011) highlight some uncertainties linked to the evaluation of modelled wet deposition,

14 as a result of insufficient measurements of atmospheric concentrations of many key

15 compounds (e.g. $\mathrm{HNO}_{3}$, coarse-nitrate or $\mathrm{NO}_{2}$ ) or the limited availability of measurements of gas and particle compounds at the same site, among others. Moreover, model performance evaluation of wet deposition is strongly limited by the quality of meteorological input data (e.g. precipitation on complex topography) according to the same authors.

In Europe, some studies to evaluate wet deposition predictions for individual models have been carried out. The performance of the EMEP model for wet deposition of oxidised sulphate and oxidised and reduced nitrate has been evaluated with EMEP observations for several decades, and results can be found in EMEP status reports (http://emep.int). In the most 23 recent report (for the year of 2014; Gauss et al. 2015, 24 http://emep.int/publ/reports/2015/sup Status Report 1 2015.pdf) the authors found some overestimation of reduced nitrogen deposition, (12\%), a small positive bias for oxidized nitrogen (1\%), and an underestimation of sulphur wet deposition (-35\%), considering annual accumulated values. The EMEP model was also evaluated in Simpson et al. (2006), in which the authors mention a slight overestimate of wet deposition of sulphur when compared with the measurements of the EMEP network. Aksoyoglu et al. (2014) showed that the modelled total nitrogen deposition for CAMx at various locations in Switzerland for 2006 was in the same range as the measured values. Nevertheless, comparison of the modelled wet deposition with measurements in the same study revealed an underestimation by a factor of two for 
1 oxidized nitrogen, although model performance was better for the wet deposition of reduced

2 nitrogen (Aksoyoglu et al., pers. comm.). The LOTOS-EUROS model has been evaluated for

3 wet deposition by Schaap et al. (2004), who found an underestimation by a factor of two or

4 more for all components, on average. In Spain, Garcia-Gómez et al. (2014) evaluated the wet

5 deposition of oxidized and reduced $\mathrm{N}$ estimated by CHIMERE for the period 2005-2008,

6 using measurement data from several networks, and including a comparison with the EMEP

7 model. The authors obtained reasonable results for both models, with a slightly better

8 performance for CHIMERE in the case of oxidized nitrogen, and a worse performance for

9 reduced nitrogen (the model underestimated observed wet deposition of reduced $\mathrm{N}$ ).

10 With regards to model intercomparisons for wet deposition, several studies have been

11 published, some of them based on global model estimates (Lamarque et al., 2005, 2013;

12 Dentener et. al, 2006), mainly using a multi-model approach and on an annual basis. Solazzo

13 et al. (2012) compared the performance of some models in EU and USA in the context of

14 AQMEII, although the results are presented in a way that preserves model anonymity.

15 Emissions and boundary conditions were common for all modelling teams but meteorology and/or grid definitions were not. The authors showed large differences between models regarding wet deposition for oxidized nitrogen. In the framework of the UNECE Task Force on Measurements and Modelling (TFMM), under the Convention on Long-range Transboundary Air Pollution (LRTAP), the EURODELTA (ED) project aims to assess how well CTMs are currently able to reproduce observed pollutant air concentrations and depositions in Europe, as well as to explain the differences between their predictions. The first two phases of the ED project have also looked at the evaluation and intercomparison of models (van Loon et al., 2007; Vautard et al., 2009, showing results for air concentration). In the third phase of this project, ED3, a more homogeneous input dataset and model configuration was used; common boundary conditions, meteorology, emissions and horizontal grid. Bessagnet et al. (2016) show the performance of six state-of-the art CTMs for air concentrations of a range of pollutants for four EMEP intensive measurement periods. Here, we evaluate the wet deposition of $\mathrm{S}$ (WSOx), and that of oxidized and reduced $\mathrm{N}$ wet deposition (WNOx and WNHx, respectively), as well as the air concentrations of the deposited species. We also include the intercomparison of dry deposition for oxidized and reduced $\mathrm{N}$ (DNOx and DNHx) and S (DSOx). 


\section{Materials and methods}

\section{$3 \quad 2.1$ Model set-up and configuration}

4 Six CTMs were used to perform the simulations: CHIM (CHIMERE; version chim2013),

5 EMEP (rv 4.1.3), LOTO (LOTOS-EUROS, V1.8), CAMX (CAMx, v5.41 VBS), MINNI

6 (version 4.7) and CMAQ (V5.0.1). All models were run for the same domain and resolution

7 and with the same input data (anthropogenic emissions, meteorology, and boundary

8 conditions), with the exception of CMAQ, which used a different meteorology and

9 geographical projection (Bessagnet et al., 2016). The meteorological variables were based on the calculations of ECMWF IFS (Integrated Forecast System) at a spatial resolution of $0.2^{\circ}$. CMAQ used meteorological variables from the COSMO model in CLimate Mode (COSMOCLM) version $4.8 \mathrm{clm} 11$. The boundary layer height data used by CHIM, LOTO, and CAMX were calculated by ECMWF, whereas EMEP, MINNI and CMAQ used boundary layer heights as described in Bessagnet et al. (2016). For the boundary concentrations, MACC reanalysis (Inness et al., 2013; Benedetti et al., 2009) was used as input data for $\mathrm{O}_{3}, \mathrm{CO}, \mathrm{NO}_{2}$, $\mathrm{SO}_{2}, \mathrm{HCHO}, \mathrm{CO}_{2}, \mathrm{CH}_{4}$, sulphates, dust and carbonaceous aerosols.

Anthropogenic emissions were calculated by INERIS, by merging several databases: 1) TNO $0.125^{\circ} \times 0.0625^{\circ}$ for 2007 from MACC (Kuenen et al., 2011), 2) EMEP $0.5^{\circ} \times 0.5^{\circ}$ emission inventory for 2009 (Vestreng et al., 2007) and 3) emission data from the GAINS database (http://gains.iiasa.ac.at/gains). Emissions were re-gridded by INERIS, as described in Bessagnet et al. (2016).

Table 1 summarizes some relevant aspects of the different models, such as chemical mechanisms or other specifications for the different processes. More details of the parameterizations are provided by Bessagnet et al. (2014; 2016). Here we summarize only those most relevant to $\mathrm{N}$ and $\mathrm{S}$ deposition (Table 1).

- NO soil emissions: CHIM and MINNI used version 2.04 of MEGAN and CAMX used version 2.1 of MEGAN. CMAQ used the BEIS (Biogenic Emission Inventory System) module developed by the US EPA. EMEP calculated these emissions as described in Simpson et al. (2012) and LOTO did not include this type of emissions.

- EMEP used the EmChem09 chemical scheme (Simpson et al., 2012), CHIM used MELCHIOR2 (Lattuati, 1997), CMAQ and CAMX used CB05 (Yarwood et al., 
2005), LOTO used a modified version of CBM-IV (Sauter et al., 2012), and MINNI used SAPRC99 (Carter, 2000).

- CMAQ, CHIM and CAMX used ISORROPIA (Nenes et al., 1999) and LOTO and MINNI the ISORROPIA II model (Fountoukis and Nenes, 2007) to estimate the formation of sulphate, nitrates and ammonium and their thermodynamic equilibria. EMEP used the equilibrium thermodynamic model MARS (Binkowski and Shankar,1995). The system modelled by ISORROPIA includes $\mathrm{NH}_{4}{ }^{+}, \mathrm{Na}^{+}, \mathrm{Cl}^{-}, \mathrm{NO}_{3}{ }^{-}$, $\mathrm{SO}_{4}{ }^{2-}$, and $\mathrm{H}_{2} \mathrm{O}$, which are partitioned between gas, liquid and solid phases, taking into account the ambient relative humidity and temperature (Nenes et al., 1998). ISORROPIA II also includes the thermodynamics of crustal species $\left(\mathrm{Ca}_{2}{ }^{+}, \mathrm{K}^{+}, \mathrm{Mg}^{2+}\right)$. MARS is another widely used model for the sulphate-nitrate-ammonia-water system (Saxena et al., 1986). ISORROPIA and, MARS account for the T-dependence of the equilibrium coefficients, although MARS uses activity coefficients calculated at $298.15 \mathrm{~K}$.

- EMEP, LOTO and CMAQ consider the formation of nitrates in the coarse fraction, originating from sea salt (all three models) and dust (only EMEP). CHIM considers a mass transfer from smaller particle sizes to larger ones, but nitrate is not directly formed in the coarse fraction. CAMX and MINNI did not consider coarse nitrate.

- EMEP, CHIM, CMAQ, CAMX and MINNI consider both, in-cloud and below-cloud wet scavenging, whereas LOTO considers just below cloud wet scavenging.

- EMEP and LOTO include a compensation point for $\mathrm{NH}_{3}$ that takes into account an equilibrium between $\mathrm{NH}_{3} / \mathrm{NH}_{4}^{+}$stored in plants and soil and $\mathrm{NH}_{3}$ concentrations in the air (reference EMEP, Wichink Kruit et al., 2012)

- CMAQ also includes emissions of sea salt sulphates corresponding to a proportion of $7.76 \%$ of emitted sea salts split into the accumulation and coarse modes.

More specific information for each model regarding wet and dry deposition is included in Annex 1. For dry deposition, although many models use a similar approach for simulating dry deposition, differences can arise from the input data required to estimate the different resistances. For example, the resistance attributed to vegetative surfaces has a stomatal and non-stomatal component. For the estimation of the stomatal resistance, a minimum resistance is used, modulated by several factors that depend on light, temperature, radiation and other variables that alter this minimum resistance. These factors are 
1 calculated for each type of vegetation. Therefore, both the land use database and the 2 parameters involved in the computation of the stomatal resistance (minimum and 3 modulating factors, assigned to each type of vegetation), can be a source of differences 4 between model estimates.

\section{$6 \quad 2.2$ Evaluation methodology}

7 All models simulated the accumulated daily deposition of WSOx (wet deposition of oxidized 8 sulphur species), WNHx (wet deposition of reduced nitrogen species), WNOx (wet deposition 9 of oxidized nitrogen species), DSOx (dry deposition of oxidized sulphur species), DNHx, (dry 10 deposition of reduced nitrogen species) and DNOx (dry deposition of oxidized nitrogen 11 species). Species included in each group are shown in Table 2.

12 In order to evaluate model performance for WNOx, WNHx and WSOx, a statistical analysis 13 was carried out, by comparing model outputs with observations. This comparison was also 14 done for air concentrations of TNO3 (the sum of nitric acid and nitrates), TNH4 (sum of $\mathrm{NH}_{3}$ 15 and ammonium) and TSO4 (sum of $\mathrm{SO}_{2}$ and sulphates).

16 A similar evaluation was not possible for dry deposition of nitrates (DNOx), ammonium 17 (DNHx) and sulphates (DSOx) due to lack of measurements. 
1 Table 1.Characteristics of model codes, for some processes directly affecting wet deposition.

2 IC: in-cloud; $\mathrm{BC}$ below-cloud ; $\mathrm{SC}$ scavenging coefficients ; ASC: Aqueous $\mathrm{SO}_{2}$ chemistry

\begin{tabular}{|c|c|c|c|c|c|c|}
\hline MODEL & EMEP & CHIM & LOTO & CMAQ & MINNI & CAMX \\
\hline $\begin{array}{l}\text { Wet Deposition: } \\
\text { Gases }\end{array}$ & $\begin{array}{l}\text { IC\& BC SC } \\
\text { (Simpson et al., } \\
\text { 2012) }\end{array}$ & $\begin{array}{l}\text { IC\& BC SC } \\
\text { (Menut et al., 2013) }\end{array}$ & $\begin{array}{l}\text { BC SC } \\
\text { Scott (1979) }\end{array}$ & $\begin{array}{l}\text { IC\& BC SC } \\
\text { Chang et al. (1987) }\end{array}$ & $\begin{array}{l}\text { IC\& BC SC } \\
(\text { EMEP, 2003) }\end{array}$ & $\begin{array}{l}\text { IC\& BC SC } \\
\text { (Seinfeld and Pandis, 1998) }\end{array}$ \\
\hline $\begin{array}{l}\text { Wet Deposition: } \\
\text { Particles }\end{array}$ & $\begin{array}{l}\text { IC\& BC SC } \\
\text { (Simpson et al. } \\
\text { 2012) }\end{array}$ & $\begin{array}{l}\text { IC\& BC SC } \\
\text { (Menut et al.. 2013) }\end{array}$ & $\begin{array}{l}\text { BC SC } \\
\text { Scott (1979) }\end{array}$ & $\begin{array}{l}\text { IC\& BC SC } \\
\text { Chang et al. (1987) }\end{array}$ & $\begin{array}{l}\text { IC\& BC SC } \\
\operatorname{EMEP~(2003)~}\end{array}$ & $\begin{array}{l}\text { IC\& BC SC } \\
\text { (Seinfeld and Pandis, 1998) }\end{array}$ \\
\hline $\begin{array}{l}\text { Gas Phase } \\
\text { Chemistry }\end{array}$ & $\begin{array}{l}\text { EmChem09 } \\
\text { (Simpson et al., } \\
\text { 2012) }\end{array}$ & $\begin{array}{l}\text { MELCHIOR2 } \\
\text { (Lattuati, 1997) }\end{array}$ & $\begin{array}{l}\text { TNO-CBM-IV } \\
\text { (Sauter et al) }\end{array}$ & $\begin{array}{l}\text { CB05* (Yarwood et al., } \\
\text { 2005) }\end{array}$ & $\begin{array}{l}\text { SAPRC99 } \\
\text { (Carter, 2000) }\end{array}$ & CB05 (Yarwood et al., 2005) \\
\hline $\begin{array}{l}\text { Cloud Chemistry: } \\
\text { Aqueous } \mathrm{SO}_{2} \\
\text { chemistry }\end{array}$ & $\begin{array}{l}\text { Yes } \\
\text { (Simpson et al., } \\
2012)\end{array}$ & $\begin{array}{l}\text { Yes and pH } \\
\text { dependent } \mathrm{SO}_{2} \\
\text { chemistry } \\
\text { (Menut et al., 2013) }\end{array}$ & $\begin{array}{l}\text { Yes } \\
\text { (Banzhaf et al. } \\
\text { 2012) }\end{array}$ & $\begin{array}{l}\text { Yes (Walcek and Taylor, } \\
\text { 1986) }\end{array}$ & $\begin{array}{l}\text { Yes (Seinfeld and } \\
\text { Pandis, 1998) }\end{array}$ & $\begin{array}{l}\text { Yes } \\
\text { RADM-AQ (Chang et al., 1987) }\end{array}$ \\
\hline Coarse Nitrate & Yes & No $(* *)$ & Yes & Yes & No & No \\
\hline $\begin{array}{l}\text { Ammonium } \\
\text { Nitrate } \\
\text { Equilibrium }\end{array}$ & $\begin{array}{l}\text { MARS } \\
\text { (Binkowski and } \\
\text { Shankar,1995) }\end{array}$ & $\begin{array}{l}\text { ISORROPIA } \\
\text { (Nenes et al., 1999) }\end{array}$ & $\begin{array}{l}\text { ISORROPIA v.2 } \\
\text { Fountoukis and } \\
\text { Nenes } 2007\end{array}$ & $\begin{array}{l}\text { ISORROPIAv1.7 } \\
\text { (Nenes et al., 1998) }\end{array}$ & $\begin{array}{l}\text { ISORROPIA v1.7 } \\
\text { (Nenes et al., } \\
\text { 1998) }\end{array}$ & ISORROPIA (Nenes et al., 1998) \\
\hline
\end{tabular}

$3 *$ with chlorine chemistry extensions

$4 \quad * *$ reaction with $\mathrm{Ca}$ or $\mathrm{Na}$ but coarse might exists with transfer from finer particles 
2 Table 2: Composition of wet and dry deposited species

\begin{tabular}{|l|l|}
\hline Deposition type & Deposited species \\
\hline W or DSOx & $\mathrm{SO}_{2}, \mathrm{SO}_{4}^{2-} ; \mathrm{H}_{2} \mathrm{SO}_{4}$ \\
\hline W or DNOx & $\begin{array}{l}\mathrm{HNO}_{3}, \mathrm{NO}_{3}^{-}, \mathrm{NO}, \mathrm{NO}_{2} \text { (and minor species } \\
\text { like } \mathrm{N}_{2} \mathrm{O}_{5}, \mathrm{PAN} \text { for some models) and HONO }\end{array}$ \\
\hline W or DNHx & $\mathrm{NH}_{3}, \mathrm{NH}_{4}^{+}$ \\
\hline
\end{tabular}

\section{$4 \quad$ 2.2.1 Observation datasets}

5 For this study we used the available EMEP measurements made during four intensive periods:

6 1-30 June 2006 (C6), 8 Jan-4 Feb 2007 (C7), 17 Sep-15 Oct 2008 (C8) and 25 Feb-26 Mar

72009 (C9). The measurement data were downloaded from the EBAS database ${ }^{1}$. All the

8 information regarding the measurement stations is available from the EBAS web site

9 http://www.nilu.no/projects/ccc/network/index.html. For this study we used daily values for

10 both deposition (WNOx, WNHx, WSOx) and mean air concentrations (TNO3, TNH4, TSO4).

11 Measurements for a given day were taken from 24-hour sampling periods. It is important to

12 note that the starting times of these sampling periods are not the same for all stations, and can

13 vary in the range $00 \mathrm{~h} 00-09 \mathrm{~h} 00$. It is also important to remark that the suite of pollutants

14 measured at each site is not the same. Table S.7.2 in the Supplementary Material lists the sites

15 and pollutants measured at each site.

16 All the sites with a temporal coverage greater than $75 \%$ were used and model values were 17 taken only when observations were available. Two sets of sites were selected: 1) all sites with wet deposition data ( $\mathrm{W}$ in Table 7) and 2) all sites with simultaneous measurements of wet deposition and air concentrations (WT, tables 8 and 9). The first dataset allows the most complete evaluation of wet deposition, as there are more stations with wet deposition (W)

21 than with total precursor air concentrations (gas and aerosol components, T), whereas the

\footnotetext{
${ }^{1}$ EBAS is a database hosting observation data of atmospheric chemical composition and physical properties. EBAS hosts data submitted by data originators in support of a number of national and international programs ranging from monitoring activities to research projects. EBAS is developed and operated by the Norwegian Institute for Air Research (NILU). For a complete list of programmes and projects for which EBAS serves as a database, please consult the information box in the Framework filter of the web interface (http://ebas.nilu.no/)
} 
1 second dataset allows us to analyse the quality of the model estimates of $\mathrm{W}$ in terms of the 2 quality of modelled $\mathrm{T}$, in order to help explain model performance.

\section{$4 \quad$ 2.2.2 Performance metrics used}

5 To evaluate model performance, the root mean square error (RMSE), bias and the spatial 6 correlation coefficient (SC) were estimated for deposition, air concentration and precipitation. 7 For deposition and precipitation, we used the accumulated values for each period. For 8 concentrations, we used the mean concentration for each period, based on daily values.

9 Definition of these metrics is included in Table 3.

10 Table 3. Statistics used to evaluate model performance.

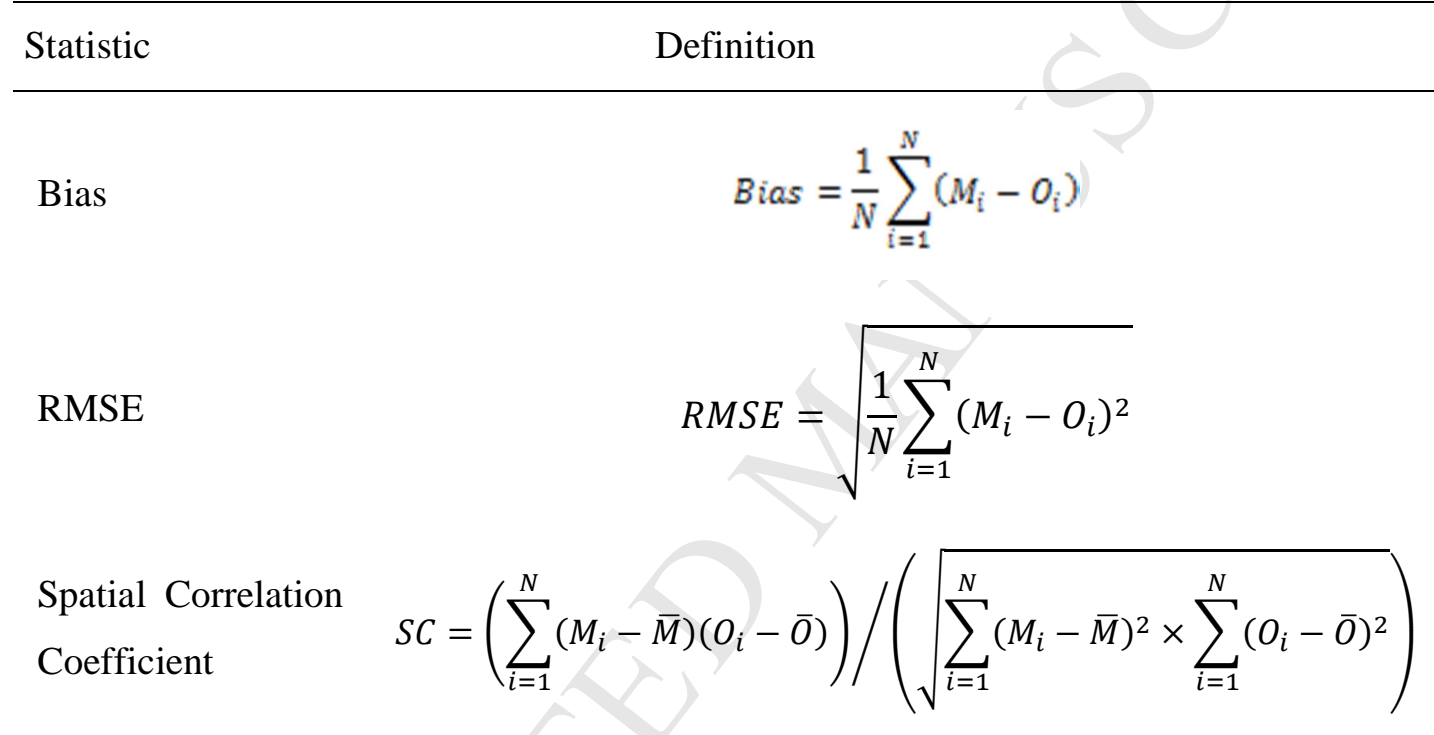

11 i subindex indicates a given site

12 
1 To facilitate the analysis, we have defined some ratios between variables, as follows:

2

4 5

$$
F_{w}=W /(C P) \text { and } F_{d}=D /(C)
$$

Eq. 1

where $\mathrm{W}$ is wet deposition, $\mathrm{D}$ is dry deposition, $\mathrm{C}$ is the atmospheric concentration (of total reduced/oxidized nitrogen or sulphur) near ground level and $\mathrm{P}$ is precipitation, for each model time-step or measurement period.

We will refer to them as the deposition factor for wet $\left(\mathrm{F}_{\mathrm{w}}\right)$ and dry $\left(\mathrm{F}_{\mathrm{d}}\right)$ deposition throughout this paper. These ratios have been calculated for both the observed and modelled values.

The analysis of wet deposition can be taken a step further to separate the contributions of gaseous and aerosol species to the deposition flux. Although we can split the measured and modelled concentrations into the gaseous and aerosol components we do not know how each phase contributes to the wet deposition (W). However, these contributions can be estimated using regression techniques. If we assume that $F_{w}$ has contributions from wet deposition of both gaseous and aerosol species, Equation 1 can be written as:

$$
W / P=F_{w, g a s} C_{g a s}+F_{w, a e r} C_{a e r}
$$

where $\mathrm{F}_{\mathrm{w} \text {,gas }}$ and $\mathrm{C}_{\mathrm{gas}}$ are the deposition factor and concentration for the gaseous species and $\mathrm{F}_{\mathrm{w}, \text { aer }}$ and $\mathrm{C}_{\mathrm{aer}}$ are the deposition factor and concentration for the aerosol species. Estimates of the phase-specific deposition factors (and their uncertainty), for the models only, were obtained using multiple linear regression, based on the equation above and considering the 287 sites where measurements of any pollutant are available (S.7.1). It is important to bear in mind that the air concentrations used in the calculation are those of the first model layer (or the measurement height), while wet deposition is calculated in the models from all the layers within and below clouds. Therefore, differences in wet deposition factors of the models are not necessarily due to differences in the deposition parameterizations, they could also be due to other factors such as differences in vertical concentration profiles. However, despite these limitations we believe that these ratios are a useful tool for highlighting differences between model estimates of atmospheric deposition and providing clues as to the reasons for these differences. This analysis can provide modellers with information that can help them to understand, and if necessary, improve model estimates. 
1 Maps of variability were also calculated to highlight the areas where models differ more and

2 areas where models give more similar results. These maps were created by considering a

3 coefficient of variation VAR of the "ensemble", defined as follows (Bessagnet et al., 2016):

4

5

6 With $C_{m}$ the concentration of individual model $m$ included in the ensemble (CHIM, LOTO,

7 MINNI and EMEP; see Bessagnet et al. 2016 for further details of the ensemble), $\mathrm{M}$ is the number of models, and $\mathrm{C}_{\mathrm{ENS}}$ is the ensemble mean concentration.

9

\section{Results and discussion}

11 The following subsections include the discussion of results for sulphur and nitrogen 12 compounds, in terms of both deposition and air concentration. For each subsection we first 13 present an evaluation of model performance and then we compare model results. Maps 14 showing WSOx, WNHx and WNOx for all campaigns and models are shown in Figures 1-3, 15 and the corresponding aerosol+gas air concentrations TSO4, TNH4 and TNO3 are shown in 16 Figures 4-6. For dry deposition, maps of DSOx, DNHx and DNOx are presented in the 17 Supplementary Material S.2.1, S.2.2 and S.2.3.

Regarding precipitation, maps and a statistical evaluation of model performance are included in the Supplementary Material S.4.1. and Table 4 (a,b,c), respectively. The maps indicate that CMAQ has a lower accumulated rainfall for all periods, when compared with the other models (especially in C6, C8 and C9). Tables 4a, 4b, 4c, showing model performance for rain, for those sites with available measurements of WSOx (Table 4a), WNHx (Table 4b) and WNOx (Table 4c) show that this model underestimates rainfall, while the other models agree

24 better with the observations, except in C6, when they tend to overestimate. 

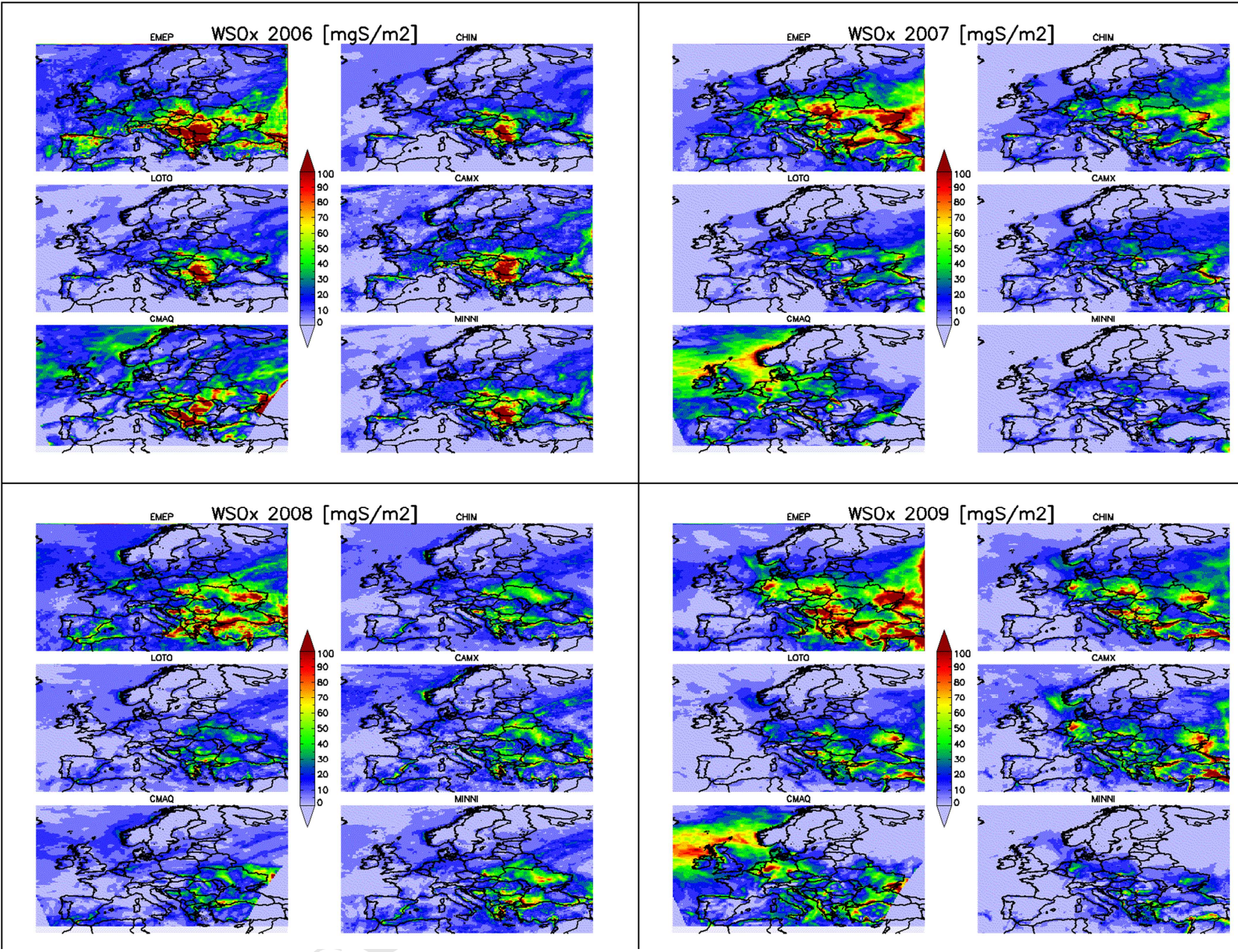

Figure 1. Accumulated deposition maps for WSOx (in $\mathrm{mgS} / \mathrm{m}^{2}$ ), for all the models and periods 


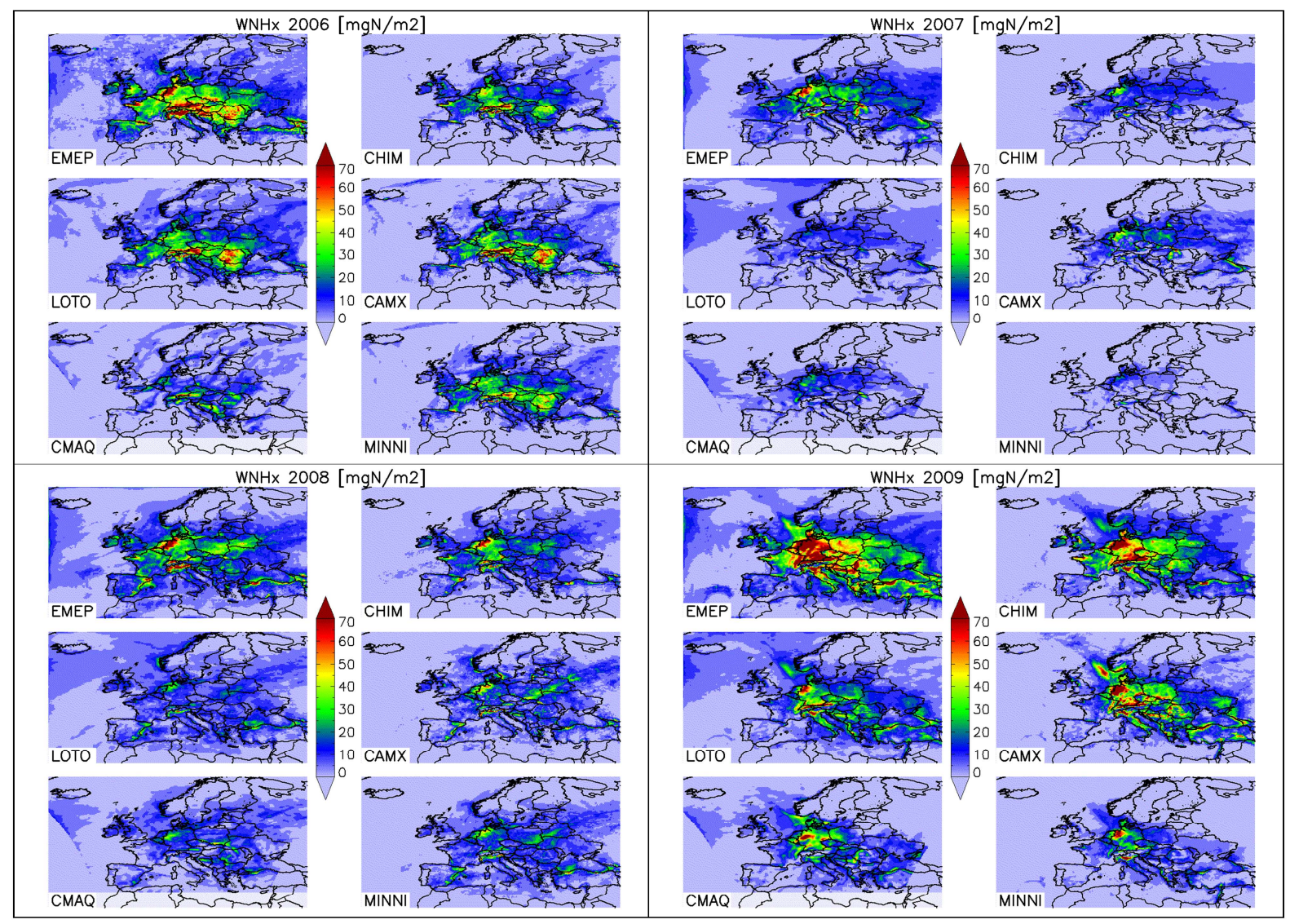

Figure 2. Accumulated deposition maps for $\mathrm{WNHx}$ (in $\mathrm{mgN} / \mathrm{m}^{2}$ ) for all the models and periods. 


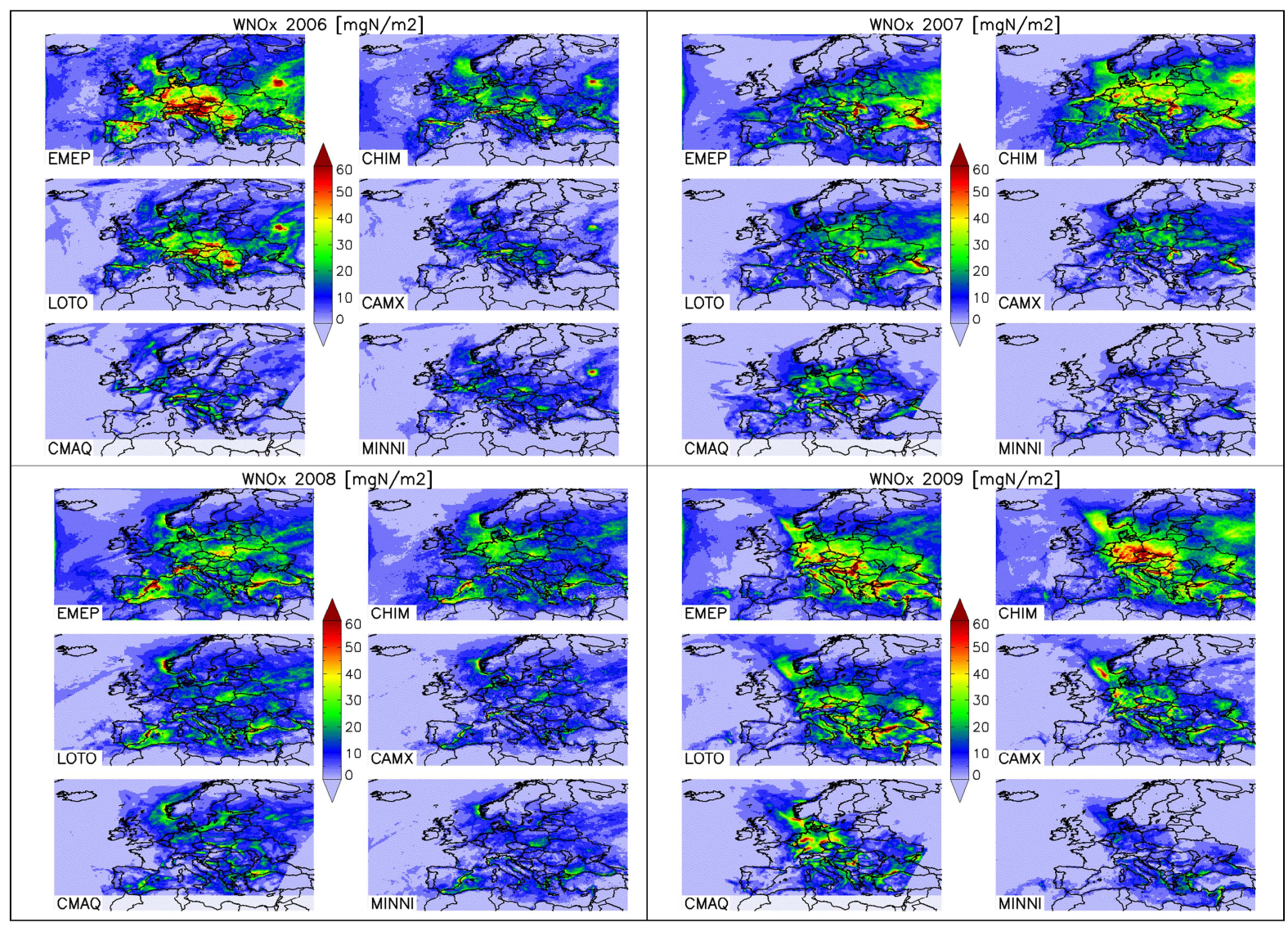

Figure 3. Accumulated deposition maps for $\mathrm{WNOx}$ (in $\mathrm{mgN} / \mathrm{m}^{2}$ ) for all the models and periods. 


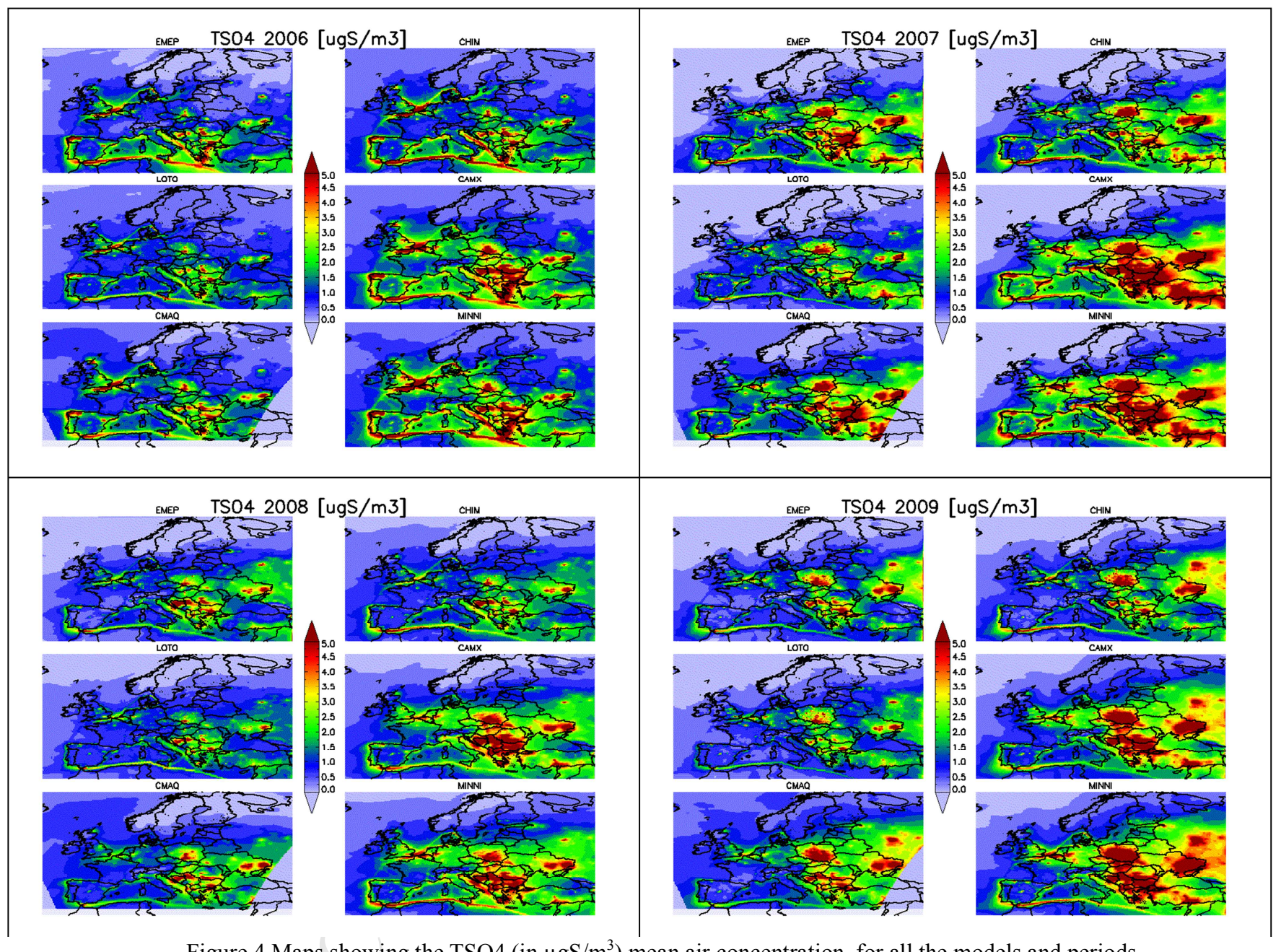

Figure 4.Maps showing the $\mathrm{TSO} 4$ (in $\mu \mathrm{gS} / \mathrm{m}^{3}$ ) mean air concentration, for all the models and periods. 


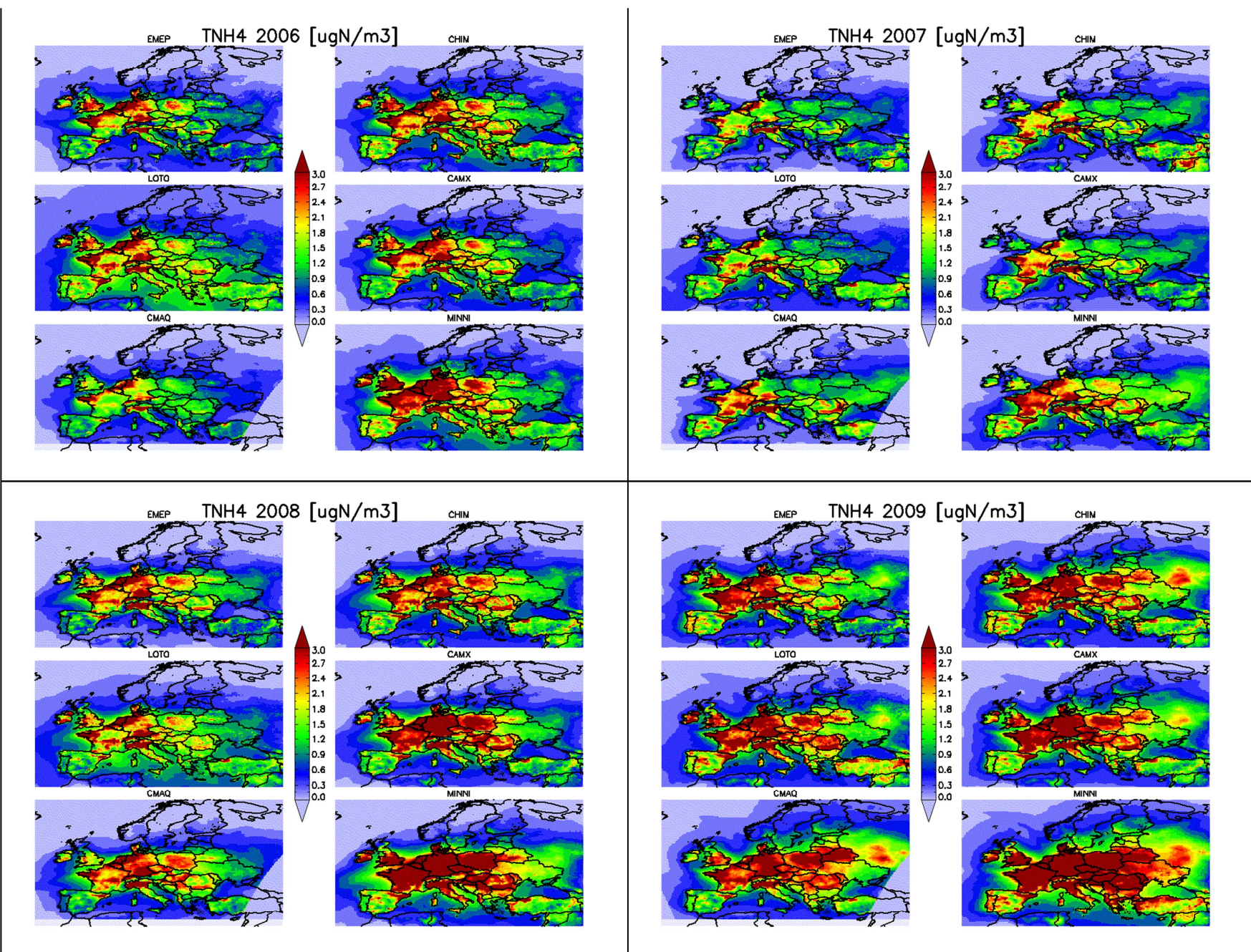




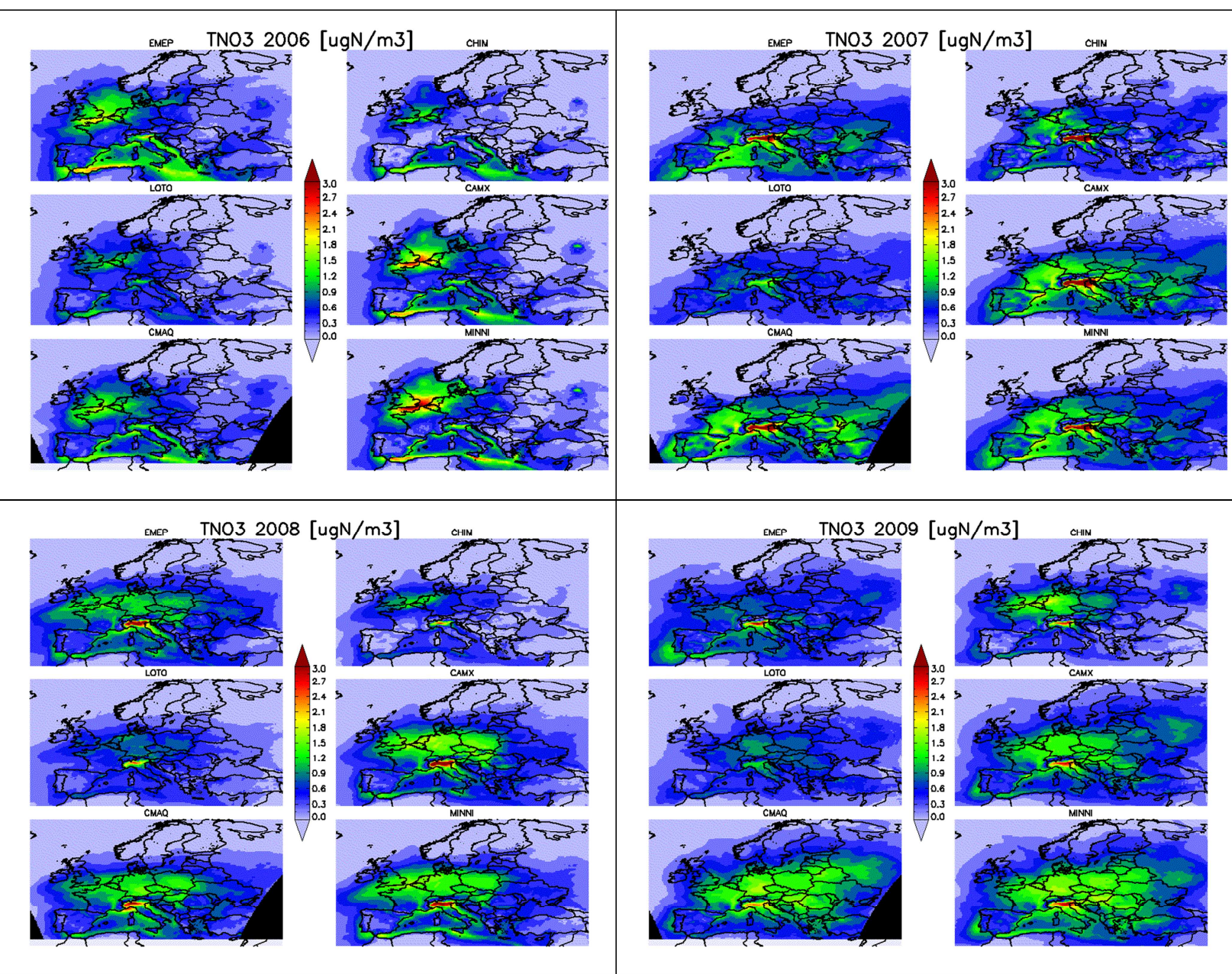

Figure 6. Maps showing the $\mathrm{TNO} 3\left(\right.$ in $\mu \mathrm{gN} / \mathrm{m}^{3}$ ) mean air concentration, for all the models and periods. 
40 Table 4a. Statistical results for rain $(\mathrm{mm})$ considering the sites with WSOx measurements

\begin{tabular}{|c|c|c|c|c|c|c|c|c|c|c|c|c|c|c|c|c|}
\hline & MOD & BIAS & $\mathrm{SC}$ & RMSE & MOD & BIAS & $\mathrm{SC}$ & RMSE & MOD & BIAS & SC & RMSE & MOD & BIAS & $\mathrm{C}$ & RMSE \\
\hline Rain & \multicolumn{4}{|c|}{2006} & \multicolumn{4}{|c|}{2007} & \multicolumn{4}{|c|}{2008} & \multicolumn{4}{|c|}{2009} \\
\hline $\mathrm{OB} / \mathrm{N}^{*}$ & \multicolumn{4}{|c|}{$50.66 / 58$} & \multicolumn{4}{|c|}{$66.66 / 59$} & \multicolumn{4}{|c|}{$62.11 / 61$} & \multicolumn{4}{|c|}{$62.24 / 42$} \\
\hline CAMX & 69.37 & 18.71 & 0.81 & 33.79 & 77.26 & 10.60 & 0.82 & 31.06 & 71.69 & 9.57 & 0.83 & 35.29 & 71.87 & 9.62 & 0.65 & 43.59 \\
\hline CHIM & 65.21 & 14.55 & 0.82 & 29.99 & 70.84 & 4.18 & 0.82 & 29.48 & 66.25 & 4.14 & 0.83 & 34.02 & 66.78 & 4.54 & 0.65 & 42.18 \\
\hline CMAQ & 39.61 & -11.05 & 0.19 & 48.69 & 52.77 & -13.89 & 0.27 & 54.83 & 56.16 & -5.96 & 0.77 & 38.53 & 33.70 & -28.54 & 0.45 & 57.08 \\
\hline EMEP & 66.24 & 15.58 & 0.79 & 32.57 & 78.97 & 12.31 & 0.78 & 35.12 & 69.76 & 7.65 & 0.81 & 36.60 & 68.81 & 6.57 & 0.67 & 41.54 \\
\hline LOTO & 63.88 & 13.21 & 0.82 & 30.05 & 71.59 & 4.93 & 0.83 & 28.71 & 65.77 & 3.65 & 0.82 & 34.81 & 65.38 & 3.14 & 0.68 & 41.10 \\
\hline MINNI & 66.17 & 15.50 & 0.80 & 33.15 & 78.29 & 11.63 & 0.83 & 31.61 & 70.66 & 8.54 & 0.81 & 36.40 & 73.69 & 11.45 & 0.68 & 42.38 \\
\hline
\end{tabular}


Table 4b. Statistical results for rain (mm) considering the sites with WNHx measurements

\begin{tabular}{|c|c|c|c|c|c|c|c|c|c|c|c|c|c|c|c|c|}
\hline & MOD & BIAS & $\mathrm{SC}$ & RMSE & MOD & BIAS & SC & RMSE & MOD & BIAS & SC & RMSE & MOD & BIAS & SC & RMSE \\
\hline Rain & \multicolumn{4}{|c|}{2006} & \multicolumn{4}{|c|}{2007} & \multicolumn{4}{|c|}{2008} & \multicolumn{4}{|c|}{2009} \\
\hline $\mathrm{OB} / \mathrm{N}^{*}$ & \multicolumn{4}{|c|}{$49.19 / 46$} & \multicolumn{4}{|c|}{$68.75 / 61$} & \multicolumn{4}{|c|}{$57.16 / 64$} & \multicolumn{4}{|c|}{$65.65 / 63$} \\
\hline CAMX & 63.42 & 14.23 & 0.76 & 31.4 & 77.77 & 9.03 & 0.82 & 31.23 & 66.13 & 8.97 & 0.64 & 34.82 & 69.52 & 3.87 & 0.48 & 58.49 \\
\hline CHIM & 59.68 & 10.49 & 0.76 & 28.60 & 71.32 & 2.57 & 0.82 & 30.18 & 61.39 & 4.23 & 0.66 & 33.75 & 64.35 & -1.30 & 0.49 & 57.60 \\
\hline CMAQ & 36.84 & -12.35 & 0.57 & 32.52 & 52.93 & -15.81 & 0.29 & 55.40 & 50.68 & -6.47 & 0.59 & 39.05 & 33.40 & -32.25 & 0.30 & 71.09 \\
\hline EMEP & 62.74 & 13.55 & 0.71 & 31.23 & 79.63 & 10.89 & 0.78 & 35.09 & 64.53 & 7.37 & 0.63 & 36.36 & 65.98 & 0.33 & 0.52 & 56.38 \\
\hline LOTO & 62.74 & 13.55 & 0.71 & 31.23 & 72.30 & 3.55 & 0.83 & 29.10 & 60.59 & 3.43 & 0.64 & 34.37 & 62.72 & -2.93 & 0.50 & 57.62 \\
\hline MINNI & 60.72 & 11.53 & 0.75 & 32.65 & 78.7 & 9.95 & 0.82 & 31.67 & 65.77 & 8.61 & 0.62 & 35.91 & 70.13 & 4.48 & 0.52 & 56.94 \\
\hline
\end{tabular}

44 Table 4c. Statistical results for rain $(\mathrm{mm})$ considering the sites with WNOx measurements

\begin{tabular}{|c|c|c|c|c|c|c|c|c|c|c|c|c|c|c|c|c|}
\hline Rain & \multicolumn{4}{|c|}{2006} & \multicolumn{4}{|c|}{2007} & \multicolumn{4}{|c|}{2008} & \multicolumn{4}{|c|}{2009} \\
\hline $\mathrm{OB} / \mathbf{N}^{*}$ & \multicolumn{4}{|c|}{$53.9 / 62$} & \multicolumn{4}{|c|}{$69.31 / 62$} & \multicolumn{4}{|c|}{$62.16 / 65$} & \multicolumn{4}{|c|}{$68.2 / 64$} \\
\hline CAMX & 70.16 & 16.26 & 0.82 & 31.6 & 78.14 & 8.83 & 0.82 & 30.98 & 70.75 & 8.59 & 0.82 & 34.82 & 72.11 & 3.91 & 0.48 & 58.33 \\
\hline CHIM & 65.91 & 12.01 & 0.82 & 28.05 & 71.68 & 2.37 & 0.82 & 29.96 & 65.38 & 3.21 & 0.82 & 33.75 & 66.67 & -1.53 & 0.5 & 57.3 \\
\hline CMAQ & 41.03 & -12.87 & 0.66 & 32.91 & 53.8 & -15.51 & 0.3 & 54.95 & 54.41 & -7.75 & 0.76 & 39.05 & 34.5 & -33.7 & 0.32 & 71.12 \\
\hline EMEP & 69.38 & 15.48 & 0.78 & 33.01 & 80 & 10.7 & 0.78 & 34.8 & 68.84 & 6.68 & 0.8 & 36.36 & 68.5 & 0.3 & 0.53 & 55.98 \\
\hline LOTO & 69.38 & 15.48 & 0.78 & 33.01 & 72.66 & 3.35 & 0.84 & 28.89 & 64.94 & 2.77 & 0.81 & 34.37 & 65.47 & -2.72 & 0.51 & 57.35 \\
\hline MINNI & 65.78 & 11.88 & 0.8 & 30.96 & 79.03 & 9.72 & 0.82 & 31.41 & 70.16 & 8 & 0.8 & 35.91 & 72.79 & 4.6 & 0.53 & 56.58 \\
\hline
\end{tabular}




\subsubsection{WSOx: Evaluation of model results}

The model performance statistics for WSOx are presented in Tables 5 and 6, using sea salt corrected and non-corrected observations, respectively. As mentioned above, CMAQ considers sulphate emissions that originate from sea salt, while the rest of the models do not. For this reason the statistics for all models with the exception of CMAQ should be discussed using the data in Table 5 (sea salt corrected observations), whereas for CMAQ, the data in Table 6 (not sea salt corrected) should be used. The results in Table 6 for the non-corrected data show that CMAQ performs best for $\mathrm{C} 7$ and $\mathrm{C}$, and is among the best for C6 (CAMX performs better). It is useful to analyse how the models behave at sites affected by sea salt emissions. Figure S.4.8 shows modelled and observed WSOx at a station located in the North of Spain (ES08). CMAQ is the only model capable of reproducing the large measured values of WSOx at this site. Figure S.4.9 shows an example for two sites located in Ireland, IE08 and IE09. This figure shows non-corrected (a) and sea salt corrected (b) data. The sea salt correction applied and available from the EBAS website shows a clear and strong effect of sea salt on WSOx at this site. In this case, we can again see how CMAQ is the only model that can reproduce the high observed values, when no sea salt correction is applied. These graphics show that 1) sulphates emitted with sea salt can have a significant contribution to deposited sulphates, and 2) models should include sea salt sulphate to adequately reproduce measured deposited rates. For the corrected data, the other models perform quite well.

Table 5, calculated with observed data after correction for sea salt, shows that CAMX performs best overall in C9 for WSOx (CMAQ is not included in this comparison). However, CAMX overestimates TSO 4 by the largest amount, after MINNI. As pointed out in the following section, graphs in the Supplementary Material S.4.5 show that CAMX predicts the smallest dry deposition rates (along with MINNI) for a given TSO4. At the same time, maps of SO2 concentrations in the Supplementary Material (S.4.1) show that CAMX predicts the largest SO2 concentrations for most of the periods. According to Pirovano et al. (2012), this model seems to have a stronger downward mixing than the other models, enhancing the influence of elevated sources (especially relevant in the case of SO2) on ground level concentrations. All these factors can enhance the accumulation of sulphate at the surface 
layer, and thus the good results for WSOx for CAMX could be partially due to compensating factors, and could hide problems, such as an underestimation of dry deposition.

MINNI and LOTO underestimate WSOx for all periods, MINNI especially in C9 and LOTO especially in C6. At the same time, MINNI overestimates TSO4. Figure S.4.4 shows that for the same amount of rain, MINNI has a lower wet deposition than the other models in C7 and C9. All these factors suggest that MINNI has a low wet deposition efficiency, which could be due to several reasons, such as an underestimation of scavenging ratios, large vertical concentration gradients, resulting in small concentrations at cloud height, or a problem with the modelling of clouds. In the case of LOTO, the underestimation of WSOx is consistent with Schaap et al. (2004). Again, Figure S.4.4 shows a lower wet deposition for this model in C6 for the same amount of rain, when compared with the other models. Figure 7, showing values of Fw for sulphur (from now on FSO4), indicates lower values of FSO4 for this model compared with the observed values, which suggests a low wet deposition efficiency for this model. This behaviour can partially be explained by the lack of in-cloud scavenging in this model, as sulphate is largely produced in the cloud aqueous phase.

By contrast, EMEP overestimates WSOx during all four periods, with the highest bias in C7. This model has the smallest (positive) bias for TSO4, compared with the other models, with larger values in C7 and C8, and overestimates rain, except in C9 (see Table 4a). The fact that this model overestimated WSOx without underestimating TSO4 could also indicate an underestimation of sulphur dry deposition. In fact, the scatter plots of TSO4 against dry deposition in Figure S.4.5, show that EMEP has large differences to some of the other models, such as CMAQ and CHIMERE in C6 and C7, with lower dry deposition values.

CHIMERE also partially overestimates TSO4 concentrations but has a very different performance for WSOx, which is underestimated in summer (C6) and overestimated in winter (C7). The behaviour in summer seems to indicate a low scavenging efficiency, producing a low WSOx and consequently high TSO4. This can be also inferred from Figure 7, where FSO4 is underestimated at some sites in C6. In C7 FSO4 for CHIMERE is correctly modelled, and thus the simultaneous overestimate of TSO4 and WSOx seems to suggest an overestimate of $\mathrm{SO} 2$ air concentration or an overestimate of SO2 oxidation (considering that dry deposition for this model is high, compared with the others). 
106 Finally, it should be mentioned that a better spatial coverage of measurements would allow a 107 more complete evaluation since there are areas with large differences between models, for 108 which no evaluation is possible. 
1 Table 5. Statistical results for sea-salt corrected WSOx (mgS/m2) and TSO4 (ugS/m3) using all the available sites

\begin{tabular}{|c|c|c|c|c|c|c|c|c|c|c|c|c|c|c|c|c|}
\hline all & MOD & BIAS & SC & RMSE & MOD & BIAS & SC & RMSE & MOD & \begin{tabular}{|l|l} 
BIAS & $S$
\end{tabular} & SC & RMSE & MOD & BIAS & $\mathbf{S C}$ & RMSE \\
\hline WSOx & \multicolumn{4}{|c|}{2006} & \multicolumn{4}{|c|}{2007} & \multicolumn{4}{|c|}{2008} & \multicolumn{4}{|c|}{2009} \\
\hline 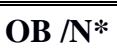 & \multicolumn{4}{|c|}{$22.88 / 46$} & \multicolumn{4}{|c|}{$14.86 / 49$} & \multicolumn{4}{|c|}{$13.76 / 50$} & \multicolumn{4}{|c|}{$17.45 / 42$} \\
\hline CAMX & 24.45 & 1.58 & 0.72 & 14.62 & 14.88 & 0.02 & 0.64 & 9.64 & 14.27 & 0.45 & 0.49 & 11.71 & 18.26 & 0.81 & 0.7 & 12.89 \\
\hline CHIM & 16.95 & -5.93 & 0.49 & 17.29 & 21.92 & 7.06 & 0.67 & 16.83 & 13.51 & -0.3 & 0.5 & 11.26 & 22.19 & 4.74 & 0.54 & 18.6 \\
\hline CMAQ & 23.23 & 0.35 & 0.38 & 18.85 & 27.37 & 12.51 & 0.42 & 22.25 & 9.98 & -3.74 & 0.51 , & 11.82 & 20.34 & 2.9 & 0.28 & 23.88 \\
\hline EMEP & 31.02 & 8.14 & 0.57 & 19.89 & 25.97 & 11.11 & 0.64 & 21.35 & 18.37 & 4.62 & 0.45 & 13.19 & 26.6 & 9.15 & 0.68 & 18.82 \\
\hline LOTO & 14.44 & -8.43 & 0.63 & 15.81 & 12.05 & -2.81 & 0.65 & 10.01 & 9.51 & -4.25 & 0.54 & 11.76 & 13.54 & -3.91 & 0.68 & 13.63 \\
\hline MINNI & 18.45 & -4.43 & 0.52 & 16.89 & 7.97 & -6.88 & 0.62 & 11.55 & 10.61 & -3.14 & 0.49 & 11.81 & 6.66 & -10.79 & 0.58 & 18.39 \\
\hline TSO4 & \multicolumn{4}{|c|}{$\begin{array}{c}1.06 / 19 \\
\end{array}$} & \multicolumn{4}{|c|}{$0.69 / 23$} & \multicolumn{4}{|c|}{$0.61 / 17$} & \multicolumn{4}{|c|}{$\begin{array}{l}0.86 / 17 \\
\end{array}$} \\
\hline CAMX & 1.66 & 0.6 & 0.87 & 0.76 & 1.24 & 0.56 & 0.65 & 1.02 & 1.32 & 0.71 & 0.89 & 1.01 & 1.4 & 0.54 & 0.92 & 0.65 \\
\hline CHIM & 1.24 & 0.18 & 0.66 & 0.65 & 0.86 & 0.17 & 0.55 & $\begin{array}{l}0.71 \\
\end{array}$ & 0.88 & 0.27 & 0.83 & 0.43 & 0.95 & 0.09 & 0.8 & 0.39 \\
\hline CMAQ & 1.14 & 0.09 & 0.88 & 0.28 & 0.98 & 0.3 & 0.52 & 0.18 & 0.84 & 0.23 & 0.9 & 0.35 & 1.15 & 0.29 & 0.91 & 0.38 \\
\hline EMEP & 1.11 & 0.05 & 0.7 & 0.5 & 0.87 & 0.18 & 0.58 & 0.7 & 0.85 & 0.24 & 0.81 & 0.48 & 0.89 & 0.03 & 0.89 & 0.29 \\
\hline LOTO & 1.06 & 0.01 & 0.77 & 0.36 & 0.78 & 0.09 & 0.56 & 0.7 & 0.76 & 0.14 & 0.84 & 0.3 & 0.8 & -0.06 & 0.82 & 0.34 \\
\hline MINNI & 1.79 & 0.73 & 0.78 & 1.02 & 1.36 & 0.68 & 0.61 & 1.13 & 1.4 & 0.78 & 0.86 & 1.03 & 1.63 & 0.77 & 0.9 & 0.91 \\
\hline
\end{tabular}

*OB/N: OB: observed value in $\mathrm{mgS} / \mathrm{m}^{2}$ for $\mathrm{WSOx}$ and $\mathrm{ugS} / \mathrm{m}^{3}$ for TSO4; $\mathrm{N}$ : number of sites 
1 Table 6. Statistical results for WSOx $\left(\mathrm{mgS} / \mathrm{m}^{2}\right)$ and TSO4 (ugS $/ \mathrm{m}^{3}$, without sea salt correction) using all the available sites

\begin{tabular}{|c|c|c|c|c|c|c|c|c|c|c|c|c|c|c|c|c|}
\hline All & MOD & BIAS & SC & RMSE & MOD & BIAS & $\mathrm{SC}$ & RMSE & MOD & BIAS & SC & RMSE & MOD & BIAS & SC & RMSE \\
\hline WSOx & \multicolumn{4}{|c|}{2006} & \multicolumn{4}{|c|}{2007} & \multicolumn{4}{|c|}{2008} & \multicolumn{4}{|c|}{2009} \\
\hline $\mathrm{OB} / \mathrm{N}^{*}$ & \multicolumn{4}{|c|}{$28.25 / 57$} & \multicolumn{4}{|c|}{$30.17 / 57$} & \multicolumn{4}{|c|}{$24.47 / 61$} & \multicolumn{4}{|c|}{$22.34 /: 62$} \\
\hline CAMX & 28.29 & 0.05 & 0.68 & 17.38 & 14.81 & -15.37 & 0.19 & 33.22 & 15.74 & -8.73 & 0.54 & 37.86 & 17.55 & 4.79 & 0.64 & 16.12 \\
\hline CHIM & 20.12 & -8.13 & 0.54 & 19.83 & 21.15 & -9.03 & 0.08 & 35.11 & 15.12 & -9.35 & 0.4 & 39.83 & 19.57 & $-2,77$ & 0.42 & 20.29 \\
\hline CMAQ & 27.98 & -0.26 & 0.66 & 17.64 & 28.18 & -2 & 0.6 & 23.81 & 10.48 & -13.86 & 0.38 & 42.25 & 20.86 & -1.48 & 0.66 & 16.35 \\
\hline EMEP & 36.39 & 8.14 & 0.56 & 22.91 & 25.8 & -4.38 & 0.12 & 34.87 & 20.98 & -3.36 & 0.54 & 36.82 & 23.83 & 1.5 & 0.54 & 19.15 \\
\hline LOTO & 17.26 & -10.98 & 0.57 & 19.95 & 11.57 & -18.6 & 0.07 & 35.84 & 10.44 & -13.90 & 0.48 & 41.45 & 12.28 & -10.06 & 0.52 & 19.77 \\
\hline MINNI & 21.26 & -6.98 & 0.48 & 20.92 & 7.87 & -22.3 & 0.19 & 36.66 & 11.95 & -12.39 & 0.23 & 42.7 & 6.21 & -16.13 & 0.5 & 23.94 \\
\hline TSO4 & \multicolumn{4}{|c|}{$1.31 / 56$} & \multicolumn{4}{|c|}{$1.04 / 58$} & \multicolumn{4}{|c|}{$1.1 / 20$} & \multicolumn{4}{|c|}{$1.07 / 34$} \\
\hline CAMX & 1.98 & 0.68 & 0.68 & 1.16 & 1.89 & 0.84 & 0.67 & 1.3 & 1.74 & 0.64 & 0.61 & 1.04 & 1.55 & 0.49 & 0.77 & 0.69 \\
\hline CHIM & 1.42 & 0.11 & 0.59 & 0.83 & 1.28 & 0.23 & 0.66 & 0.79 & 1.06 & & 0.74 & 0.33 & 0.99 & -0.07 & 0.71 & 0.44 \\
\hline CMAQ & 1.38 & 0.08 & 0.66 & 0.73 & 1.39 & 0.34 & 0.6 & 0.86 & 1.22 & 0.11 & 0.63 & 0.51 & 1.2 & 0.13 & 0.68 & 0.49 \\
\hline EMEP & 1.26 & -0.04 & 0.56 & 0.83 & 1.25 & 0.2 & 0.66 & 0.76 & & & 0.66 & 0.4 & 0.97 & -0.1 & 0.8 & 0.38 \\
\hline LOTO & 1.25 & -0.06 & 0.63 & 0.65 & 1.07 & 0.03 & 0.62 & 0.72 & & -0.15 & 0.74 & 0.36 & 0.9 & -0.17 & 0.71 & 0.46 \\
\hline MINNI & 2.01 & 0.7 & 0.63 & $1.26 \|$ & 1.96 & 0.92 & 0.67 & 1.35 & 1.72 & 0.62 & 0.64 & $0.86 \|$ & 1.7 & 0.64 & 0.74 & 0.87 \\
\hline
\end{tabular}

$3 \quad * \mathrm{OB} / \mathrm{N}$ : OB: observed value in $\mathrm{mgS} / \mathrm{m}^{2}$ for WSOx and $\mathrm{ugS} / \mathrm{m}^{3}$ for TSO4; $\mathrm{N}$ : number of sites

4 

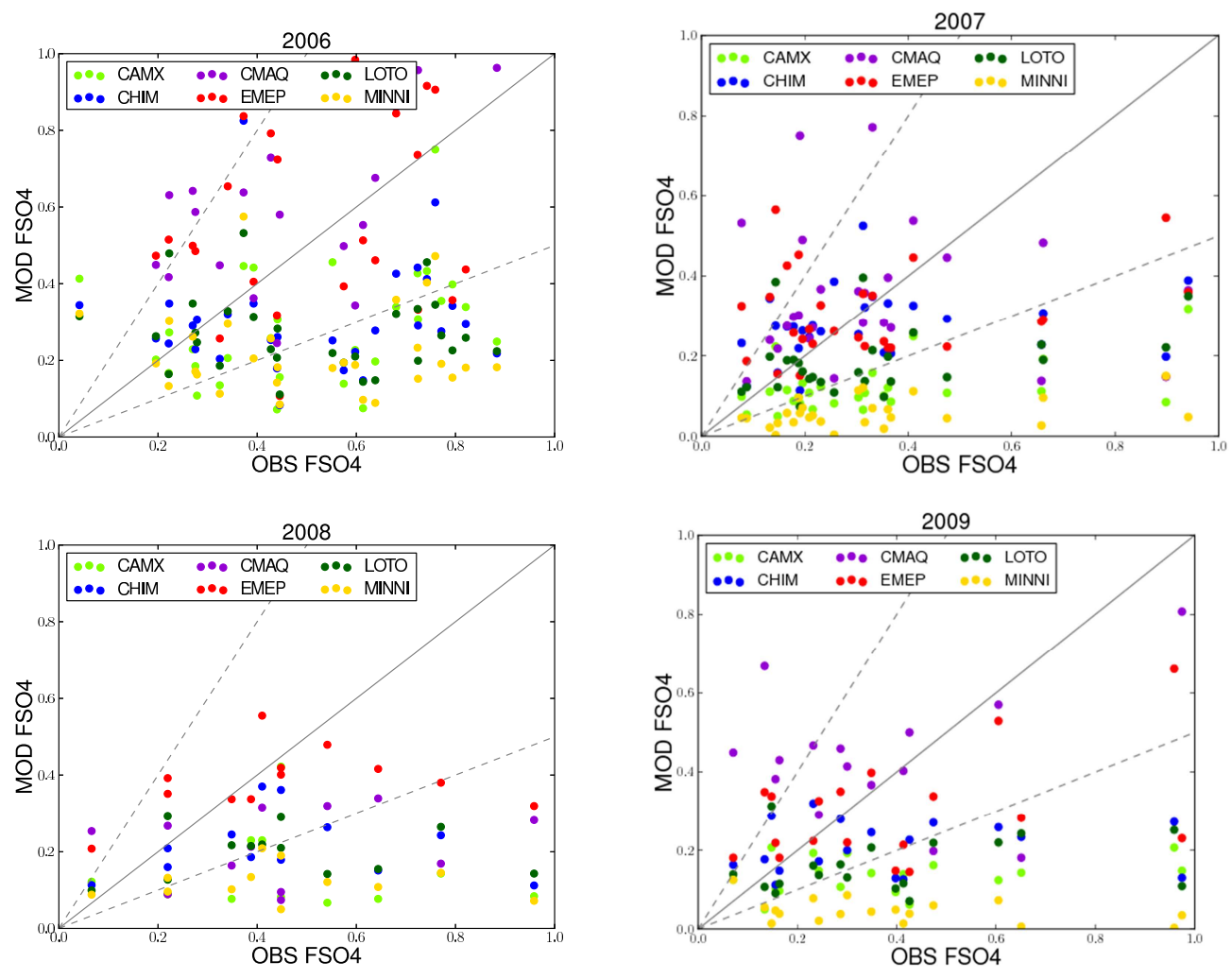

3 Figure 7. Scatter plots showing modelled and observed FSO4 (not sea salt corrected) (in $4\left(\mathrm{mgS} / \mathrm{m}^{2}\right) /\left(\mathrm{ugS} / \mathrm{m}^{3}\right) / \mathrm{mm}$, for the EMEP intensive campaigns C6, C7, C8, and C9

\section{$6 \quad 3.1 .2$ Comparison of modelled estimates}

7 Maps of WSOx show a distinct spatial pattern for CMAQ, especially in the Atlantic Ocean

8 and North Sea (Figure 1). This is because this model is the only one that considers sulphate

9 emissions from sea salt and, therefore, this model estimates higher WSOx values over marine

10 areas. For most of the campaigns EMEP estimates higher accumulated WSOx to terrestrial

11 areas than all the other models. From the maps of TSO4 (SO2+SO4-10) in Figure 4 we can

12 see that CAMX and MINNI estimate higher values than the other models, as already pointed 13 out by the comparison with observations. Bar charts of the modelled WSOx deposition factor 14 in the Supplementary Material S.4.7 show that CMAQ has the highest values for Atlantic 15 countries (Spain, Great Britain and France; consistent with sulphate sea salt emissions), 16 followed by EMEP, which has similar values to CMAQ in Germany and even higher in 
1 Poland. CAMX and MINNI estimate the lowest deposition factors for all five selected

2 countries, followed by LOTO.

3 Regarding DSOx, CMAQ estimates the highest values (S.2.3), which is also consistent with

4 the sulphate emissions from sea salt. On the other hand, both the bar and scatter plots in the

5 Supplementary Material S.4.7 show that CMAQ has the highest dry deposition factor,

6 followed by CHIM. The fact that part of the sulphates in the CMAQ simulations comes from

7 sea salt, with a fraction of these natural sulphates attributed to the coarse fraction, could be the

8 reason for a faster deposition velocity (settling velocity), compared with sulphates formed by

9 secondary processes. Scatter plots of TSO4 versus DSOx in S.4.5 indicate that CAMX and

10 MINNI predict a lower DSOx for a given TSO4 than the rest of models. The large

11 differences in the estimates of the models highlight the need of an evaluation of the dry

12 deposition process with measurements, especially when, as it can be inferred from S.4.6, the

13 magnitude of dry deposition at some points in the domain is similar to that of wet deposition,

14 and even higher for some models, such as CHIMERE or CMAQ.

\subsection{Reduced Nitrogen}

\subsubsection{Evaluation of model results}

The model evaluation statistics for WNHx and TNH4 are presented in tables 7 and 8. Results in Table 7, which use all sites with WNHx measurements, show a general underestimation for all models, with the exception of EMEP, which has lowest negative bias and even overestimates deposition in C6 and C9. These results are consistent with other publications looking at these models, such as Schaap et al. (2004) for LOTO and García-Gómez et al. (2014) for CHIMERE. In C7 the general underestimation is very pronounced, as shown in the scatter plots in Figure 8. EMEP performs best in terms of both bias and RMSE for this period while, by contrast, MINNI has the highest negative bias, accompanied by the highest RMSE. In C6 CAMX and LOTO perform best overall. For the WT sites (Table 8), all models EMEP. The fact that EMEP performs well for WNHx but underestimates TNH4 in this period could be due to several reasons, one hypothesis being the combination of an even larger underestimation of TNH4 and an overestimation of the wet deposition efficiency. As shown 
1 in S.5.7 and Figure 9, FNH4 (Fw for reduced nitrogen, that is, WNHx/TNH4/rain) estimated 2 by EMEP is generally higher than that of the other models (only CAMX in C6 is similar to 3 EMEP, with even higher values in some countries), although in C6 and C8 EMEP tends to 4 overestimate this factor. For colder periods (C7 and C9) FNH4 is correctly modelled by this 5 model. The higher WNHx loads shown by EMEP are consistent with the higher removal 6 efficiency for aerosol phase compounds shown in S.5.8., and a higher removal of the aerosol 7 phase can lead to the results shown in S.5.3, indicating that for the same TNH4, EMEP has the highest $\mathrm{NH}_{3} / \mathrm{NH}_{4}{ }^{+}$ratio. The opposite behaviour is produced by MINNI, both in S.5.8 and

9 S.5.3, thus explaining the lowest FNH4 among all models.

Scatter plots of FNH4 (Figure 9) show that all the models estimate this factor better in C6 than in C7 and C9. The largest underestimate of the wet deposition factor was in C7 and C9 for all models, with the exception of EMEP (as already noted), being more pronounced for MINNI and LOTO. This underestimation could be related to the scavenging deposition of the aerosol component, since the cooler temperatures of this campaign favoured the aerosol phase and, as shown in S.5.8, all models have a small wet deposition factor for the aerosol component, relative to that of EMEP. This figure was produced by calculating the $\mathrm{F}$ factor as discussed in Subsection 2.2.2 for the gas and aerosol species, using modelled values at 287 sites within the domain. By contrast, in $\mathrm{C} 6$ and partially in $\mathrm{C} 8$, when temperature conditions were more favourable for the gas phase, modelled estimates of FNH4 agree best with the 20 observations.

21 The frequent underestimation of both WNHx and TNH4 for some models (the only exception 22 is C9) indicates that besides the underestimation of aerosol scavenging efficiency, models are 23 also not able to reproduce the total ammonium concentration (gas+aerosol). This could be 24 caused, for example, by an underestimation of emissions or an overestimation of dry deposition rates. At this point it is interesting to remark that only EMEP and LOTO have a compensation point for $\mathrm{NH}_{3}$ dry deposition. This fact is highlighted in S.5.3 where LOTO and EMEP have higher $\mathrm{NH}_{3} / \mathrm{NH}_{4}{ }^{+}$ratios for the same TNH4 concentration, with respect to the other models. The other models do not take into account the influence of $\mathrm{NH}_{3} / \mathrm{NH}_{4}{ }^{+}$saturation of the soil and/or vegetation that would inhibit or, at least, strongly reduce, dry deposition over $\mathrm{NH}_{3}$ high emitting areas. For example, in the case of CMAQ, Figure 9 shows that the model correctly reproduces the deposition factor, while Figure S.2.2 shows that this model has the highest DNHx in C6, which decreases the TNH4 available for wet deposition. 
1 However the lower $\mathrm{NH}_{3}$ dry deposition rates in LOTO and EMEP do not clearly improve 2 their performance for TNH4 concentrations (see Table 8). Additional analyses of $\mathrm{NH}_{3}$ 3 emission rates and their temporal variation are probably needed in the future. 
1 Table 7. Statistical results for $\mathrm{WNH}_{\mathrm{x}}\left(\mathrm{mgN} / \mathrm{m}^{2}\right)$ (first part of the table) and WNOx $\left(\mathrm{mgN} / \mathrm{m}^{2}\right)$ (second part of the table) using all the available

2 EMEP sites.

3

\begin{tabular}{|c|c|c|c|c|c|c|c|c|c|c|c|c|c|c|c|c|}
\hline W & MOD & BIAS & SC & RMSE & MOD & BIAS & $\mathrm{sc}$ & RMSE & MOD & BIAS & SC & RMSE & MOD & BIAS & SC & RMSE \\
\hline WNHx & \multicolumn{4}{|c|}{\begin{tabular}{|c|}
2006 \\
\end{tabular}} & \multicolumn{4}{|c|}{2007} & \multicolumn{4}{|c|}{2008} & \multicolumn{4}{|c|}{2009} \\
\hline $\mathrm{OB} / \mathrm{N}^{*}$ & \multicolumn{4}{|c|}{$24.38 / 46$} & \multicolumn{4}{|c|}{$17.95 / 61$} & \multicolumn{4}{|c|}{$14.14 / 59$} & \multicolumn{4}{|c|}{$28.67 / 63$} \\
\hline CAMX & 20.38 & -4 & 0.87 & 12.56 & 9.23 & -8.72 & 0.5 & 15.97 & 13.23 & -0.90 & 0.55 & 10.96 & 19.32 & -9.35 & 0.6 & 27.6 \\
\hline CHIM & 17.18 & -7.2 & 0.84 & 14.31 & 8.2 & -9.75 & 0.27 & 17.9 & 16.29 & 2.15 & 0.37 & 13.18 & 24.85 & -3.82 & 0.48 & 30.36 \\
\hline CMAQ & 9.62 & -14.76 & 0.8 & 21.84 & 7.46 & -10.49 & 0.5 & 17.08 & 8.99 & -5.15 & 0.54 & 11.29 & 10.43 & -18.24 & 0.6 & 32.99 \\
\hline EMEP & 28.44 & 4.06 & 0.78 & 15.44 & 13.69 & -4.27 & 0.43 & 14.88 & 21.04 & 6.91 & 0.35 & 16.08 & 31.41 & 2.73 & 0.53 & 31.43 \\
\hline LOTO & 20.38 & -3.99 & 0.82 & 13.46 & 7.49 & -10.47 & 0.5 & 17.34 & 10.61 & -3.53 & 0.43 & 11.39 & 16.5 & -12.17 & 0.58 & 29.26 \\
\hline MINNI & 16.12 & -8.26 & 0.79 & 16.25 & 3.58 & -14.38 & 0.51 & 20.18 & 11.28 & -2.86 & 0.46 & 11.16 & 7.86 & -20.81 & 0.47 & 36.09 \\
\hline WNOx & \multicolumn{4}{|c|}{$19.39 / 62$} & \multicolumn{4}{|c|}{$17.47 / 62$} & \multicolumn{4}{|c|}{$13.98 / 65$} & \multicolumn{4}{|c|}{$22.36 / 64$} \\
\hline CAMX & 9.27 & -10.13 & 0.63 & 16.83 & 10.88 & -6.59 & 0.61 & 14.94 & 9.44 & -4.55 & 0.51 & 11.71 & 12.28 & -10.08 & 0.72 & 22.02 \\
\hline CHIM & 16.85 & -2.54 & 0.52 & 14.78 & 20.49 & 3.02 & 0.62 & 13.77 & 16.41 & 2.42 & 0.41 & 12.18 & 21.66 & -0.69 & 0.65 & 20.18 \\
\hline CMAQ & 8.57 & -10.82 & 0.6 & 17.6 & 12.89 & -4.58 & 0.63 & 14.06 & 9.59 & -4.39 & 0.56 & 11.23 & 9.77 & -12.59 & 0.7 & 24.15 \\
\hline EMEP & 29.69 & 10.3 & 0.65 & 17.94 & 13.74 & -3.73 & 0.54 & 14.67 & 19.52 & 5.54 & 0.38 & 14.34 & 18.66 & -3.7 & 0.68 & 20.03 \\
\hline LOTO & 19.94 & 0.55 & 0.6 & 14.21 & 13.33 & -4.13 & 0.66 & 13.33 & 12.91 & -1.07 & 0.49 & 11.1 & 14.3 & -8.06 & 0.71 & 21.17 \\
\hline MINNI & 9.2 & -10.19 & 0.43 & 18.33 & 4.55 & -12.92 & 0.55 & 19.65 & 7.55 & -6.43 & 0.45 & 12.84 & 3.83 & -18.52 & 0.46 & 31.06 \\
\hline
\end{tabular}


1 Table 8. Statistical results for WNHx and TNH4 $\left(\mathrm{mgN} / \mathrm{m}^{2}\right.$ and $\mathrm{ug} / \mathrm{m}^{3}$ respectively) using only the available stations with simultaneous

2 measurements of both pollutants

3

\begin{tabular}{|c|c|c|c|c|c|c|c|c|c|c|c|c|c|c|c|c|}
\hline WT & MOD & BIAS & $\mathrm{SC}$ & RMSE & MOD & BIAS & SC & RMSE & MOD & BIAS & SC & RMSE & MOD & BIAS & SC & RMSE \\
\hline WHx & \multicolumn{4}{|c|}{2006} & \multicolumn{4}{|c|}{2007} & \multicolumn{4}{|c|}{2008} & \multicolumn{4}{|c|}{2009} \\
\hline OB / N $^{*}$ & \multicolumn{4}{|c|}{$20.98 / 23$} & \multicolumn{4}{|c|}{$16.4 / 29$} & \multicolumn{4}{|c|}{$14.5 / 27$} & \multicolumn{4}{|c|}{$21.69 / 22$} \\
\hline CAMX & 13.2 & -7.79 & 0.83 & 12.64 & 8.87 & -7.53 & 0.42 & 15.44 & 12.04 & -2.46 & 0.35 & 14.46 & 17.92 & -3.77 & 0.33 & 23.1 \\
\hline CHIM & 10.83 & -10.15 & 0.8 & 13.49 & 8.18 & -8.23 & 0.13 & 17.51 & 14.07 & -0.43 & 0.16 & 16.17 & 21.78 & 0.09 & 0.29 & 28.44 \\
\hline CMAQ & 8.01 & -12.97 & 0.7 & 16.34 & 6.87 & -9.53 & 0.35 & 16.75 & 8.02 & -6.48 & 0.59 & 12.48 & 7.59 & -14.1 & 0.38 & 23.2 \\
\hline EMEP & 21.51 & 0.52 & 0.8 & 12.52 & 13.02 & -3.38 & 0.21 & 16.12 & 19.5 & & 0.19 & 17.8 & 27.66 & 5.97 & 0.28 & 32.75 \\
\hline LOTO & 14.09 & -6.89 & 0.75 & 12.06 & 7.41 & -8.99 & 0.37 & 16.43 & 9.88 & -4.62 & 0.22 & 13.84 & 15.8 & -5.9 & 0.31 & 23.24 \\
\hline MINNI & 12.12 & -8.86 & 0.64 & 14.26 & 3.28 & -13.12 & 0.25 & 19.41 & 10.11 & -4.39 & 0.26 & 13.87 & 6.79 & -14.9 & 0.32 & 24.05 \\
\hline TNH4 & \multicolumn{4}{|c|}{$2.51 / 23$} & \multicolumn{4}{|c|}{$1.67 / 29$} & \multicolumn{4}{|c|}{$1.7 / 27$} & \multicolumn{4}{|c|}{$2.23 / 22$} \\
\hline CAMX & 1.64 & -0.87 & 0.75 & 1.31 & 1.57 & -0.1 & 0.68 & 1.21 & 1.95 & 0.25 & 0.67 & 1.21 & 2.68 & 0.46 & 0.68 & 1.68 \\
\hline CHIM & 1.88 & -0.63 & 0.8 & 1.2 & 1.69 & 0.02 & 0.66 & 1.33 & 1.76 & 0.05 & 0.71 & 0.97 & 2.49 & 0.27 & 0.74 & 1.22 \\
\hline CMAQ & 1.16 & -1.34 & 0.79 & 1.61 & 1.52 & -0.15 & 0.79 & 0.97 & 1.57 & -0.13 & 0.73 & 0.8 & 2.44 & 0.21 & 0.73 & 1.12 \\
\hline EMEP & 1.4 & -1.1 & 0.78 & 1.4 & 1.38 & -0.29 & 0.56 & 1.4 & 1.5 & -0.2 & 0.69 & 0.95 & 2.32 & 0.1 & 0.72 & 1.41 \\
\hline LOTO & 1.78 & -0.73 & 0.81 & 1.1 & 1.49 & -0.18 & 0.63 & 1.25 & 1.62 & -0.09 & 0.71 & 0.85 & 2.59 & 0.37 & 0.75 & 1.28 \\
\hline MINNI & 2 & -0.51 & 0.79 & 1.1 & 1.87 & 0.2 & 0.66 & 1.28 & 2.43 & 0.73 & 0.7 & 1.53 & 3.29 & 1.06 & 0.67 & 2.04 \\
\hline
\end{tabular}

*OB/N: OB: observed value in $\mathrm{mgN} / \mathrm{m}^{2}$ for $\mathrm{WNHx}$ and ug/m $/ \mathrm{m}^{3}$ for TNH4; $\mathrm{N}$ : number of sites 
2
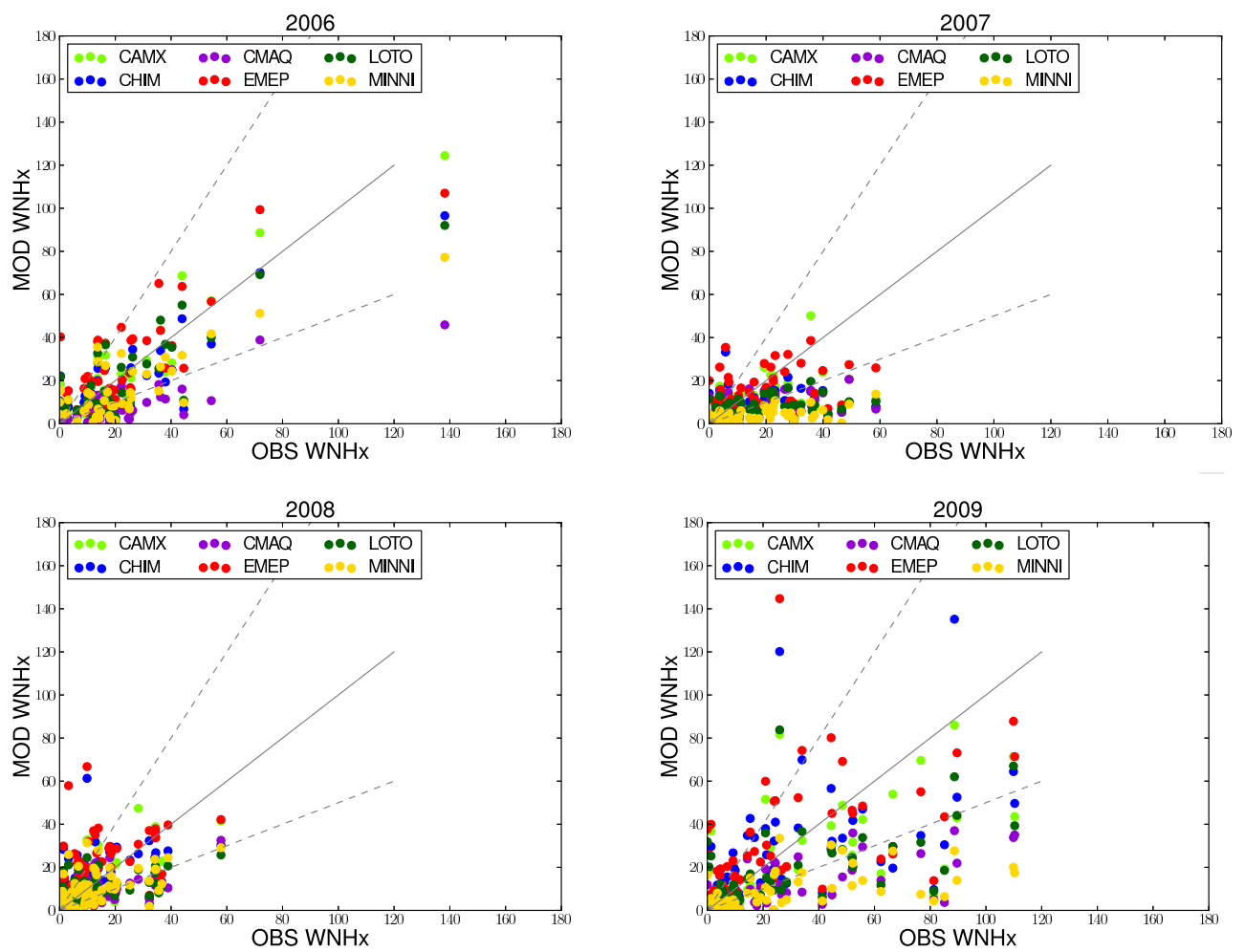

3

4 Figure 8. Scatter plots showing modelled and observed WNHx (in $\mathrm{mgN} / \mathrm{m}^{2}$ ) for the EMEP intensive campaigns $5 \quad \mathrm{C} 6, \mathrm{C} 7, \mathrm{C} 8$, and $\mathrm{C} 9$ 

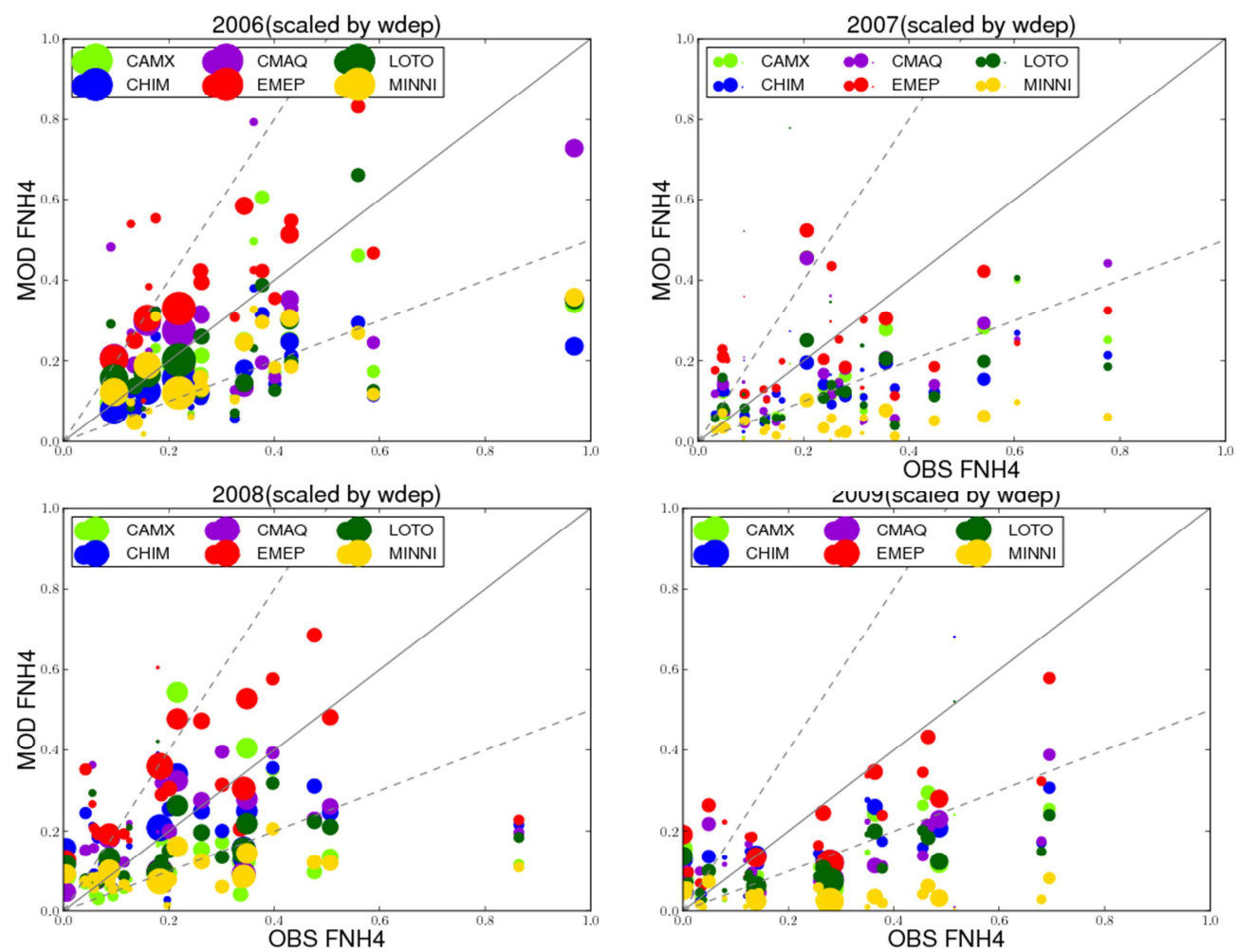

Figure 9. Scatter plots showing modelled and observed FNH4 (in $\left.\left(\mathrm{mgN} / \mathrm{m}^{2}\right) /\left(\mathrm{ugN} / \mathrm{m}^{3}\right) / \mathrm{mm}\right)$ for the EMEP intensive campaigns $\mathrm{C} 6, \mathrm{C} 7, \mathrm{C} 8$ and $\mathrm{C} 9$

4

5

6

\subsubsection{Comparison of modelled estimates}

Maps in Figure 2 show that EMEP estimates the highest WNHx for all campaigns. Figure 5 shows that MINNI estimates the highest concentrations of TNH4, with substantial differences to the other models, especially over the north Germany, northwest France and northern Italy, where the largest ammonia emissions occur. The formation of ammonium can occur in the form of both sulphates and nitrates. Ammonium concentrations were lower in C6 for all models (S.5.2). As mentioned above, this result is consistent with the fact that ammonium nitrate is a volatile species, with increasing volatility at higher temperatures and lower relative humidity. Since MINNI estimates some of the largest values of TNH4 (Figure

3 5), $\mathrm{NH}_{3}$ and $\mathrm{NH}_{4}-10$ (Supplementary Material S.5.1. and S.5.2) but with a similar rainfall

4 (Supplementary Material S.1) to the other models, this again indicates that this model has a 5 smaller wet deposition factor than the other models. EMEP and LOTO estimate the lowest 6 values of $\mathrm{NH}_{4}-10$ for all periods except C6 (S.5.2) whereas CAMX estimates the largest 7 values in $\mathrm{C} 8$. The estimated deposition factors for the gas $\left(\mathrm{NH}_{3}\right)$ and aerosol $\left(\mathrm{NH}_{4}-10\right.$, the 8 ammonium component of $\mathrm{PM}_{10}$ ) components for all measurement locations (287) over all 
1 periods (S.5.8) show that EMEP has the largest factor for both components although the

2 difference to the other models is more marked for the aerosol phase. The deposition factor for

3 the gaseous component of WNHx is smaller or of a similar magnitude to that of the aerosol.

4 Nevertheless, this is probably not a result of the model parameterizations for the two

5 components since, for example, EMEP uses a larger in-cloud scavenging ratio for $\mathrm{NH}_{3}$ than

6 for $\mathrm{NH}_{4}-10$. This suggests that the difference in the magnitude of the two factors is due to the

7 vertical concentration profiles, a hypothesis that is backed up by the fact that Erisman et al.

8 (1988) observed stronger decreases with height for $\mathrm{NH}_{3}$ concentrations compared with the

9 decreases in ammonium concentrations.

10 Maps in S.2.2 for DNHx show that CMAQ estimates some of the highest values in C6 and C9 11 (LOTO also high in C9), CMAQ has the largest dry deposition factor (S.5.7) for the countries 12 along the Atlantic coast (France, Great Britain and Spain) and LOTO has the largest over 13 Germany and Poland. The deposition factors for CAMX and EMEP are also some of the 14 highest. Scatter plots of TNH4 versus dry deposition in S.5.5 show that CHIM and MINNI 15 estimate the lowest dry deposition for a given value of TNH4, as does EMEP in C6. All models estimate the largest dry deposition in north-west France, north-west Germany and northern Italy, which are the regions with the largest ammonia emissions. Again, as discussed for DSOx, S.5.6 (a comparison of WNHx with DNHx) shows that dry deposition loads are of the same order as WNHx, or even higher for many locations in the domain and models. Therefore, it is important to have measurements that could be used to evaluate model results in order to have confidence in the $\mathrm{N}$ deposition calculated by models.

\subsection{Oxidized Nitrogen}

\subsubsection{Evaluation of model results}

Tables 7 (bottom) and 9 show the average accumulated value for WNOx, mean bias, spatial correlation and RMSE for the 4 periods. When considering all the available sites (W group, Table 7), the group of models with the lowest values of WNOx (CAMX, CMAQ and MINNI) shows a general underestimation. The predictions of MINNI have a fairly high negative bias, especially in C7 and C9, compared with the rest of the models. This confirms that the model tends to underestimate wet deposition fluxes for all three ions, despite it generally estimating higher ground level air concentrations than the other models. This means, combined with the 
1 fact that all the models except CMAQ overestimate rain, that MINNI underestimates the 2 efficiency of the wet scavenging processes at some sites, as confirmed by Figure 11. The 3 models with the highest WNOx values (EMEP, LOTO and CHIM) seem to agree better with 4 observations, although EMEP overestimates WNOx in C6 and C8, accompanied with high 5 values of RMSE.

6 For the WT group (Table 9), EMEP, LOTO and CHIM have the lowest RMSE for TNO3 for 7 most of the campaigns, with the exception of CHIM having the highest RMSE in C6, accompanied by a large negative bias. The three models, on average, perform well for WNOx, TNO3 and FNO3 (Fw for oxidised nitrogen). The main differences between these three models and CAMx, CMAQ and MINNI relies on the deposition factor for gas phase compound that, in contrast to $\mathrm{NHx}$, is more relevant for the gas phase than for the aerosol species (S.6.9). In this figure we show the deposition factors calculated for the gas and the aerosol phase (from model results at 287 sites; as explained in Section 3.2.2). We can see that for all models the scavenging efficiency of the gas phase is higher than that of the aerosol one (note that graphics in S.6.9 present a different scale for the y-axes), with EMEP having the highest values of both, followed by CHIM and LOTO.

The only relevant exception to this general behaviour is shown by CHIM in C6, where the model strongly underestimates TNO3 concentration. Despite this, CHIM does not disagree greatly with the observations in C6 for WNOx, as shown in the scatter plots of modelled versus observed WNOx (Figure 10). This fact could hide a combination of factors, such as un underestimation of TNO3 formation (we must remember that CHIMERE does not include the formation of coarse nitrates related to sea salt or dust), combined with an overestimation of wet deposition processes (pointed out in Figure 11, by the comparison of modelled and observed deposition factor (WNOx/rain/TNO3) and the overestimation of rain (Table 4c). An answer to why this model could overestimate the wet deposition factor in this campaign could come from an inadequate repartition between gas/aerosol phases for this period, when air temperatures are higher, and gas to aerosol conversion is less favoured. To investigate this idea further we have plotted TNO3 against the gas to aerosol ratio (TNO3 vs $\mathrm{HNO}_{3} / \mathrm{NO}_{3}-10$, where $\mathrm{NO}_{3}-10$ is the nitrate component of $\mathrm{PM}_{10}$ ) for $\mathrm{C} 6$ for all models (S.6.4). This plot shows the model values at 287 sites (same locations as in S.7.1) and provides information on the contribution of the gaseous and aerosol phases of TNO3. Besides the fact that EMEP (red circles) estimates higher values of TNO3, CHIM predicts a $\mathrm{HNO}_{3} / \mathrm{NO}_{3}-10$ ratio larger than 
1 one at many locations, contrary to EMEP and LOTO, for example, which predict much lower

2 ratios, with most values being lower than one. This fact combined with the higher deposition

3 factor of $\mathrm{HNO}_{3}$ compared with the aerosol component (S.6.9) could lead to an overestimation

4 of the wet scavenging strength for a given TNO3 concentration, and thus an overestimation of 5 FNO3.

6 In C6 the low bias of EMEP (almost zero) for TNO3, accompanied by an overestimation of 7 WNOx (Table 9), could hide an overestimation of TNO3 levels, which a compensated by an overestimation of rain, at least over the area covered by WT group of observations. This potential overestimation of TNO3 by EMEP could be due to the low values of dry deposition (DNOx) (S.2.3). Although we cannot conclude if this value is good or not, a low dry deposition could partly explain the presence of high TNO3 in this period of the year, when dry deposition processes are more relevant. With regards to the deposition factors (deposition normalized by TNO3 and rain), EMEP has similar values to those calculated from the observations for some sites where the model overestimates WNOx in C6 and C8 (Figure 11).

For the models that underestimate WNOx (CAMX, CMAQ and MINNI), the problem seems to be different. As mentioned previously, these models overestimate TNO3 and underestimate WNOx (except in C6, when all the models with the exception of EMEP underestimate both WNOx and TNO3). CAMX, CMAQ and MINNI also have smaller deposition factors to those calculated from the observations (Figure 11). In the case of CMAQ, the underestimate of the deposition factor suggests that rain (underestimated for this model) is not the only reason for the underestimate of WNOx. Plots in S.6.4 and S.6.9 indicate both a higher gas/aerosol ratio and lower deposition factors for these models. The more relevant role of the gas component, due to its higher deposition factor, suggests an underestimation of the gas scavenging efficiency for these models. S.6.4. also indicates a potential underestimation of the scavenging efficiency for the aerosol phase for these models, except for CMAQ, which has a similar factor for aerosol as LOTO. This fact could be related to the formation of coarse nitrates from sea-salt in these two models (and in EMEP) that can be more effectively scavenged than fine aerosols. Although MINNI uses a similar parameterization to EMEP for in cloud aerosol scavenging $\left(7 \times 10^{5}\right.$ and $2 \times 10^{5}$ for accumulation and Aitkens mode, respectively), the coefficients used are lower than those used by EMEP $\left(1 \times 10^{6}\right)$. 
1 In summary, we can say that WNOx deposition seems to be more strongly driven by $\mathrm{HNO}_{3}$

2 removal than $\mathrm{NO}_{3}{ }^{-}$. Models with higher WNOx gas deposition factors (EMEP, LOTO and

3 CHIM, S.6.9) also estimate higher WNOx loads and better performance. In the case of

4 EMEP and LOTO this implies that the $\mathrm{HNO}_{3} / \mathrm{NO}_{3}{ }^{-}$ratio is always very low for a given TNO3

5 concentration, because $\mathrm{HNO}_{3}$ is efficiently scavenged and, therefore, TNO3 is mostly

6 composed of $\mathrm{NO}_{3}{ }^{-}$(S.6.4). Nevertheless in C6, CHIM also agrees well for WNOx (similarly

7 to EMEP and LOTO deposition is driven by $\mathrm{HNO}_{3}$ removal ), but it seems that the model

8 produces less total oxidized nitrogen and, moreover, the equilibrium is shifted towards the gas

9 phase fraction (S.6.4) As a consequence modelled TNO3 is underestimated and the deposition

10 factor overestimated. This result suggests that CHIM chemical and physical processes

11 involving oxidized nitrogen as well as aerosol-gas phase equilibrium (e.g. the role of

12 temperature) should be analysed further. MINNI, CAMX and CMAQ seem to underestimate

13 the gas scavenging efficiency for all campaigns (as well as that of the aerosol, although the

14 wet scavenging of $\mathrm{HNO}_{3}$ has a larger influence), leading to low wet deposition loads and high 15 air concentration. 
1 Table 9. Statistical results for WNOx and TNO3 (in $\mathrm{mgN} / \mathrm{m}^{2}$ and $\mathrm{ug} / \mathrm{m}^{3}$ respectively) using only the available stations with simultaneous

2 measurements of both pollutants

\begin{tabular}{|l|c|c|c|c|c|c|c|c||c|c|c|c||c|c|c|c|}
\hline WT & MOD & BIAS & SC & RMSE & MOD & BIAS & SC & RMSE & MOD & BIAS & SC & RMSE & MOD & BIAS & SC & RMSE \\
\hline WNOx & \multicolumn{3}{|c|}{$\mathbf{2 0 0 6}$} & \multicolumn{3}{|c|}{$\mathbf{2 0 0 7}$} \\
\hline OB /
\end{tabular}



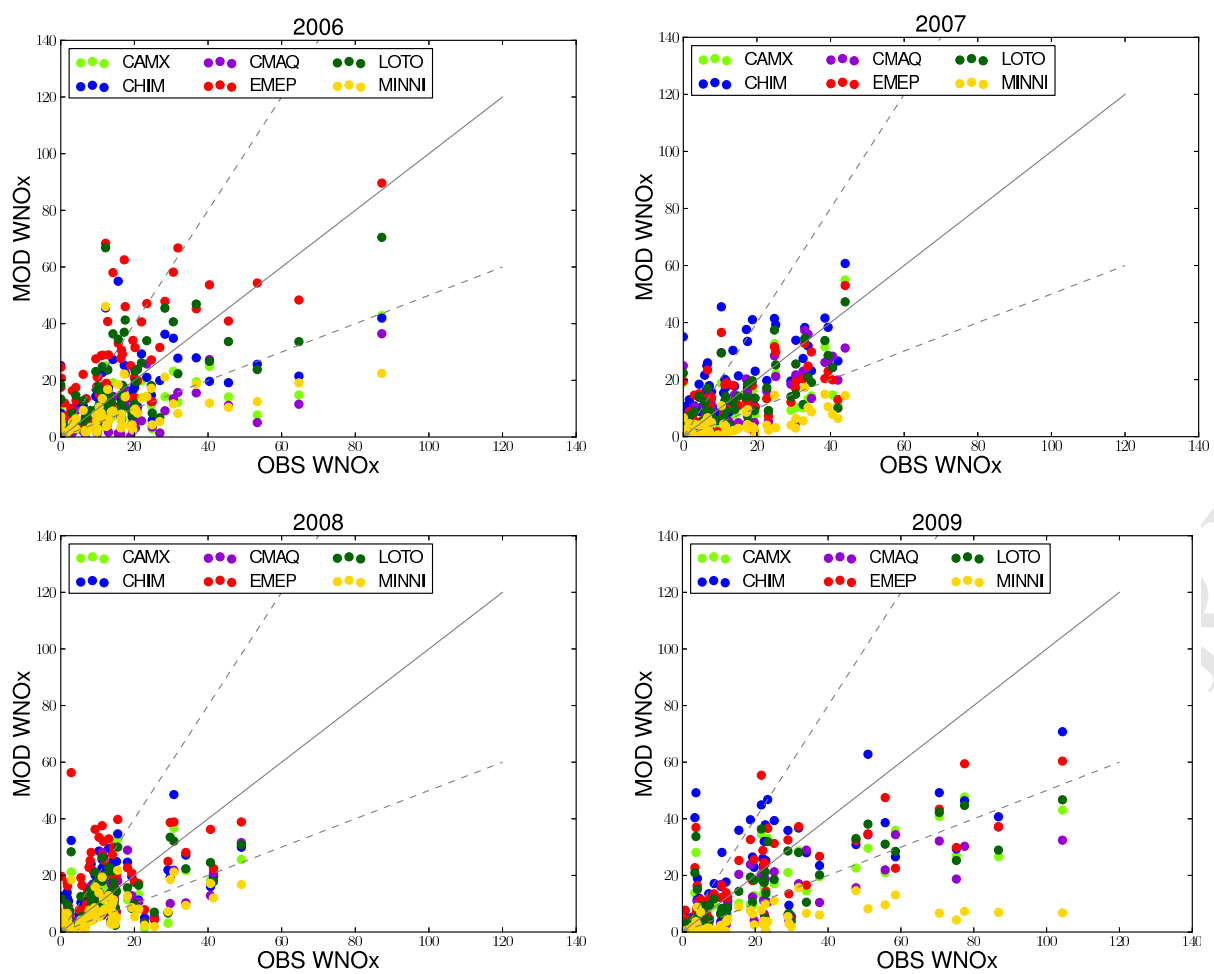

$\frac{2}{3}$

Figure 10. Scatter plots showing modelled and observed WNOx (in $\mathrm{mgN} / \mathrm{m}^{2}$ ) for all the periods
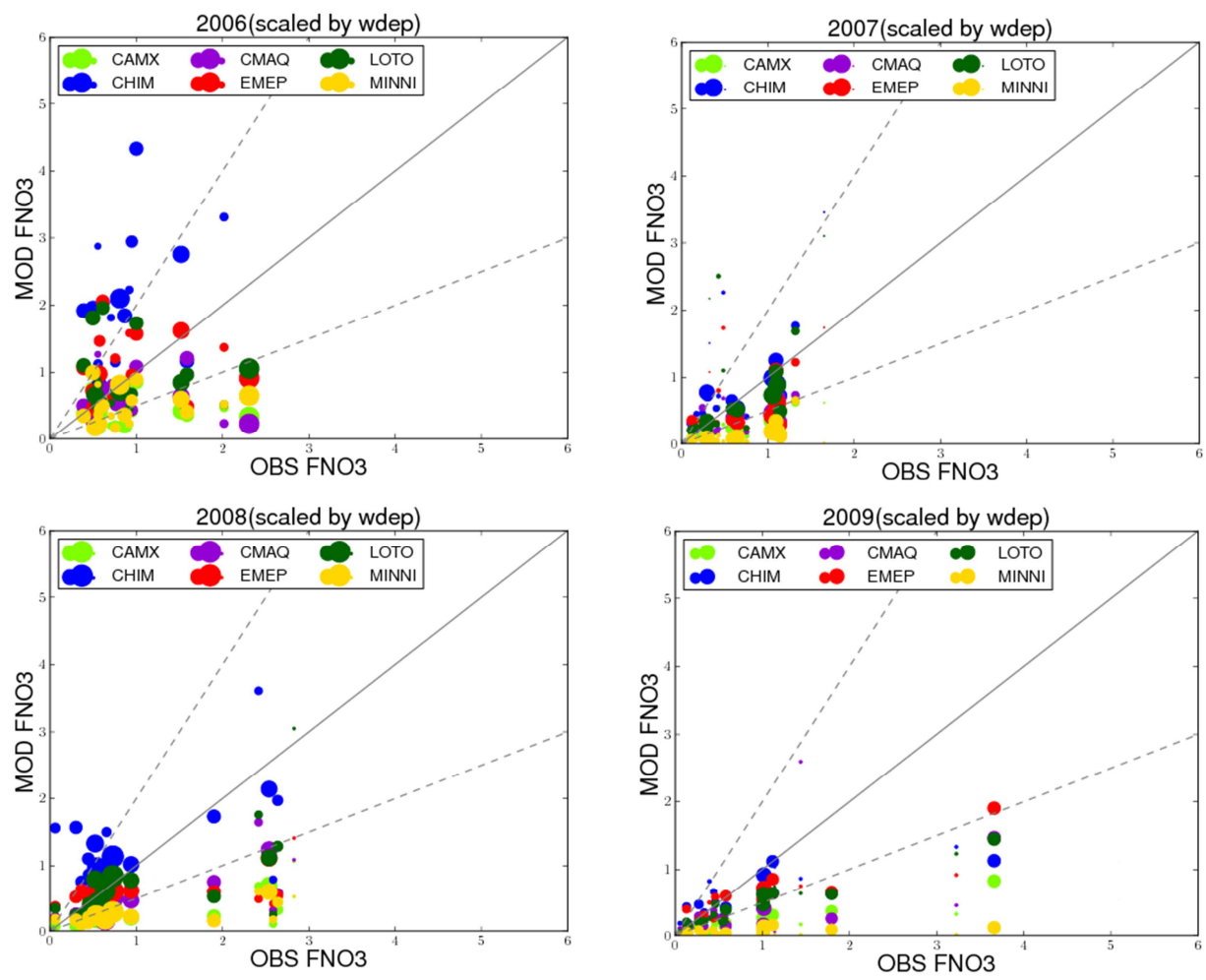

4

Figure 11. Scatter plots showing modelled and observed FNO3 (in $\left.\left(\mathrm{mgN} / \mathrm{m}^{2}\right) /\left(\mathrm{ugN} / \mathrm{m}^{3}\right) / \mathrm{mm}\right)$ for all the periods 


\section{$2 \quad 3.2 .2$ Comparison of modelled estimates}

3 For WNOx (Figure 3) there are large differences between the accumulated deposition 4 estimates of the models, with CHIM, EMEP and LOTO estimating the highest values, 5 although spatial distributions are similar. EMEP estimates particularly high values in C6 and 6 CHIM in C9, when compared with the other models. CMAQ, CAMX and MINNI estimated 7 the smallest accumulated deposition, with MINNI giving particularly small values for all four 8 periods. Maps of variability in S.3.3 show that the extent to which the models differ varies 9 depending on the period. For example, differences between models are larger in C6 over the 10 Spanish Mediterranean coast (as they are for the other species, S.3.1 and S.3.2), whereas at 11 the Norwegian coast differences are larger in C7 and C9. Since the June campaign (C6) is the period with the highest temperatures, gas-to-particle conversion is less favoured and so difference between model estimates for that period could be related to differences in the gas/aerosol ratio and/or the wet deposition parameterizations, especially for the gas phase component (or that of the aerosol in $\mathrm{C} 7$ and $\mathrm{C} 8$ ). Maps of concentrations of $\mathrm{HNO}_{3}$ and $\mathrm{NO}_{3}$ 10 (Supplementary Material S.6.2 and S.6.3, respectively) confirm larger values of $\mathrm{HNO}_{3}$ and smaller values of nitrate for C6 than for the other periods. Finally, some of the variability observed close to the boundaries of the domain can be related to differences in how the boundary conditions are treated by each model.

The maps of TNO3 concentrations are shown in Figure 6. All models estimate the largest TNO3 concentrations in regions with large NOx emissions such as northern Italy, around The English Channel and along the shipping routes especially in the Mediterranean (LOTO has the same distribution, although it cannot be seen clearly because of the low concentration estimates). The formation of nitrates in the coarse fraction, included in EMEP and LOTO (S.6.3), gives a different spatial pattern for these two models, with higher nitrate over the sea. CAMX and CMAQ estimate the largest $\mathrm{HNO}_{3}$ air concentrations, followed by MINNI. The high $\mathrm{HNO}_{3}$ concentrations for these models, (besides potential differences in deposition), can be due to different reasons, such as the high NOx concentrations estimated by CMAQ compared with the low values of CAMX, (Supplementary Material S.6.1), due to low NO. Overall, the three models with the lowest WNOx (CMAQ, CAMX and MINNI) predict the largest TNO3 concentrations, suggesting a lower efficiency of the deposition processes for these models. The fact that CMAQ estimates the lowest accumulated rainfall for all periods 
1 (especially in C6, C8 and C9) could partly explain why this model gives smaller WNOx than 2 EMEP, CHIM or LOTO.

3 In the Supplementary Material S.6.5 there are scatter plots of modelled WNOx versus 4 modelled rain for all models and periods for 287 locations. As mentioned for the other 5 pollutants, the locations correspond to all measurement sites measuring at least one of the 6 variables (see map in S.7.1), with the sole purpose of comparing model estimates (i.e. no 7 measurement data were used). These plots show substantial differences between the deposition estimates of the models for the same amount of rain; for instance, MINNI estimates much lower wet deposition than the other models for the same amount of precipitation, especially in $\mathrm{C} 7, \mathrm{C} 8$ and $\mathrm{C} 9$.

If we analyse the deposition factors, we can see in S.6.8 CHIM and EMEP have the largest wet deposition factors for WNOx (CHIM especially in C9, C8 and C7 and EMEP in C6). MINNI has the lowest values (also CAMx in C6). Differences between models are quite substantial. For example, in C9 differences between CHIM and MINNI are a factor of six in Poland. For the gas $\left(\mathrm{HNO}_{3}\right)$ and aerosol $\left(\mathrm{NO}_{3}-10\right)$ components, the estimated deposition factors for all measurement locations (287) over all periods (Fig S.6.4) show that CHIM and EMEP also have the largest factors for both components and MINNI and CAMX have the smallest. For all models, the deposition factor for the gaseous component is larger than that of the aerosol; i.e. the wet deposition is larger for the gaseous component for the same ground level concentration. This could be due to the different parameterisations for the gaseous and particulate phases in the models (for example, the EMEP model uses a larger in-cloud scavenging ratio for $\mathrm{HNO}_{3}$ than for $\mathrm{NO}_{3}-10$, same scheme as that for MINNI) or could be due to differences in the vertical profiles of the two components. Vertical concentration profile data are not available for the models in this exercise. In the Netherlands, Erisman et al. (1988) observed increasing $\mathrm{HNO}_{3}$ concentrations up to a height of $200 \mathrm{~m}$ and decreasing nitrate concentrations. Although these measurements were made at a specific place and time and in a different pollution climate to the current situation, such differences in the vertical profiles of the gaseous and aerosol components could explain the differences between the magnitudes of the two factors, in addition to the differences due to the parameterisations.

Regarding DNOx, maps in S.2.3 show large differences between models. CMAQ estimates the largest deposition rates for all periods, whereas EMEP estimates some of the lowest 
1 values for C7, C8 and C9. Scatter plots of TNO3 concentrations versus DNOx (S.6.6) also

2 show low dry deposition estimates for EMEP and high estimates for CMAQ for a given value

3 of TNO3. With regards to the deposition factor, bar plots in the Supplementary Material S.6.8

4 show that CMAQ, CAMX and LOTO have the largest values of Fd. The large differences in

5 the DNOx estimates of the models highlights the need for an evaluation of the dry deposition

6 process with measurement data, especially since dry deposition can be in the range of wet

7 deposition or even higher for some models (S.6.7).

\section{Conclusion}

A detailed analysis has been performed based on the results of four intensive EMEP measurement periods (25 Feb - 26 Mar, 2009; 17 Sep - 15 Oct, 2008; 8 Jan - 4 Feb, 2007 and 1-30 Jun, 2006). Here we present a joint analysis of wet and dry deposition as well as air concentrations in order to determine and understand the performance and behaviour of six air quality models for nitrogen and sulphur compounds.

For sulphur deposition, the fact that CMAQ includes emissions from sea salt results in higher estimates of WSOx over marine and coastal areas; EMEP estimates higher accumulated WSOx to terrestrial areas and CAMX and MINNI estimate higher TSO4 than the other models. The comparison with observations (with no sea salt corrections) shows that CMAQ performs best in $\mathrm{C} 6, \mathrm{C} 7$ and $\mathrm{C} 9$. At coastal sites, the sea salt correction applied to the measurements indicates a significant presence of sulphates. CMAQ is the only model that can reproduce the high measured values of WSOx, showing that model performance can be improved by including emissions of sea salt sulphates. MINNI and LOTO underestimate WSOx for all periods, MINNI especially in C9 and LOTO especially in C6. As MINNI overestimates TSO4, this model seems to have a low wet deposition factor for sulphur. This could be due to the vertical concentration profiles or a poor in-cloud scavenging, which in turn could be due to the parameterization of clouds in this model. By contrast, EMEP overestimates WSOx, partly due to an overestimate of precipitation, but this may also be related to an overestimate of TSO4 (due to the coarse spatial resolution used, the models are expected to overestimate $\mathrm{SO} 2$ concentrations at background locations). FSO4 (wet deposition factor for sulphates) estimated by EMEP, agrees reasonably well with that calculated from the observations, although there is a tendency to overestimate at the sites with the lowest values calculated from the observations (especially in C6 and C7), and underestimate at the sites 
1 with the highest values. CAMX performs best overall in C9 for the sea salt corrected dataset,

2 although this could be due to compensating factors, as this model overestimates TSO4 by the

3 largest amount, after MINNI. The fact that CAMX estimates the highest SO2 concentrations

4 and the lowest dry deposition rates for a given TSO4 (along with MINNI) seems to indicate a

5 small dry deposition factor (or deposition velocity), at least compared with other models.

6 CMAQ estimates the highest DSOx values, consistent with the fact that this model includes

7 sulphate emissions from sea salt. MINNI predicts lower DSOx for a given TSO4 than the rest

8 of models.

9 With regards to reduced nitrogen, EMEP estimates the highest values of WNHx and also has the highest wet deposition factor. Considering all sites with WNHx measurements, there is a general underestimation by all models, with the exception of EMEP, which underestimates the least and even overestimates deposition in C6 and C9. In C7 the general underestimation is still more pronounced, with EMEP performing best (bias and RMSE). The estimates by MINNI and CMAQ have the highest negative bias, accompanied also by high RMSE values, 15 although this is less pronounced in C6 in the case of MINNI. An analysis of the relationships between modelled wet deposition rates and the relative concentrations of gas and aerosol species, suggests that differences in how the models parameterise the wet deposition of these species (especially the aerosol) and in the vertical concentration profiles could explain the differences between models. All models underestimate TNH4 (ammonia plus ammonium) in C6, with the estimates by CMAQ having the highest negative bias, followed by EMEP. The simultaneous underestimation of WNHx and TNH4 in C6, mostly by CMAQ, but also by CAMX, CHIM, LOTO and MINNI, suggests that uncertainties or errors in the wet deposition processes cannot explain the underestimate of TNH4 in this period. An underestimate of $\mathrm{NH}_{3}$ emissions or boundary concentrations, or an overestimate of dry deposition could explain this behaviour, however. In the case of MINNI; the high values of $\mathrm{TNH} 4, \mathrm{NH}_{3}$ and $\mathrm{NH}_{4}-10$ estimated by this model (but with a similar estimate of rainfall to the other models), could also be due to an underestimate of the wet deposition factor. This could be related to the vertical concentration profiles for this model or in-cloud processes, including the parameterization of clouds. In the case of EMEP, the good estimates of wet deposition but an underestimate of TNH4 concentrations could be due to several reasons, such as the combination of low TNH4 compensated by an overestimate of rainfall. CHIM and MINNI estimate the lowest dry deposition rates for a given value of TNH4, as does EMEP in C6. 
1 Finally, regarding oxidized nitrogen, CMAQ, CAMX, MINNI predict the lowest WNOx and

2 the highest TNO3 (nitric acid plus nitrates). A comparison with observations indicates a 3 general underestimation of WNOx by these models. The predictions of MINNI have a fairly 4 high negative bias, especially in $\mathrm{C} 7$ and $\mathrm{C} 9$, compared with the rest of the models. The 5 models with the higher WNOx estimates (EMEP, LOTO and CHIM) seem to agree better 6 with observations, although EMEP substantially overestimates in two of the campaigns (C6 7 and C8), accompanied with high values of RMSE. At the same time, the three models that underestimate deposition, overestimate TNO3 for all the campaigns, except C6. This fact can be related to a low efficiency in the wet deposition of the gas phase, as illustrated in S.6.4, and can be due to several reasons, such as low concentrations in the upper levels of the atmosphere, a poorer estimation of cloud occurrence or an underestimation of gas-scavenging coefficients. In the case of MINNI the scavenging coefficient for aerosol may also be too low. In $\mathrm{C} 6$ all the models underestimate TNO3, except EMEP, which overestimates it. In this campaign all models estimate higher $\mathrm{HNO}_{3}$ and lower nitrate concentrations than in the other campaigns, most likely as a result of the higher temperatures. EMEP and LOTO estimate lower $\mathrm{HNO}_{3}$ concentrations than the other models, especially over the sea, which is consistent with the fact that these two models consider the formation of nitrates in the coarse fraction due to the presence of $\mathrm{Na}^{+}$in sea salt emissions. CAMX, CMAQ and MINNI, in general, estimate the highest $\mathrm{HNO}_{3}$ concentrations for the whole domain.

The analysis of dry deposition highlights several important issues, such as 1) there were large differences between the model estimates and 2) dry deposition contributes significantly to the total deposition for the three deposited species, with values in the same range as wet deposition for most of the models, and with even higher values for some of them, especially for reduced nitrogen. This highlights the strong need for evaluating model performance for dry deposition, something not currently possible due to the lack of suitable measurements.

\section{Acknowledgements}

CIEMAT has been financed by the Spanish Ministry of Agriculture, Environment and Food Ministerio de Agricultura, MedioAmbiente y Alimentación. RSE contribution to this work has been financed by the Research Fund for the Italian Electrical System under the Contract 
1 Directorate for Nuclear Energy, Renewable Energy and Energy Efficiency in compliance with

2 the Decree of March 8, 2006.The computing resources and the related technical support used

3 for MINNI simulations have been provided by CRESCO/ENEAGRID High Performance

4 Computing infrastructure and its staff $[\mathrm{X}]$. The infrastructure is funded by ENEA, the Italian

5 National Agency for New Technologies, Energy and Sustainable Economic Development and

6 by Italian and European research programmes (http://www.cresco.enea.it/english). MINNI

7 participation to this project was supported by the "Cooperation Agreement for support to

8 international Conventions, Protocols and related negotiations on air pollution issues", funded

9 by the Italian Ministry for Environment and Territory and Sea.

\section{References}

12

S. Aksoyoglu, J. Keller, G. Ciarelli, A. S. H. Prévôt, and U. Baltensperger (2014). A model study on changes of European and Swiss particulate matter, ozone and nitrogen deposition between 1990 and 2020 due to the revised Gothenburg protocol. Atmos. Chem. Phys., 14, 13081-13095.

Banzhaf, S., Schaap, M., Kerschbaumer, A., Reimer, E., Stern, R., van der Swaluw, E. and Builtjes, P., 2012. Implementation and evaluation of pH-dependent cloud chemistry and wet deposition in the chemical transport model REM-Calgrid. Atmospheric Environment 49, 378$390,2012$.

Benedetti, A., Morcrette, J.-J., Boucher, O., Dethof, A., Engelen, R. J., Fisher, M., Flentje, H., Huneeus, N., Jones, L., Kaiser, J. W., Kinne, S., Mangold, A., Razinger, M., Simmons, A. J., and Suttie, M. (2009): Aerosol analysis and forecast in the European Centre for MediumRange Weather Forecasts Integrated Forecast System: 2. data assimilation. J. Geophys. Res., 114, D13205, doi:10.1029/2008JD011115, 2009

Bessagnet, B., A. Colette, F. Meleux, L. Rouïl, A. Ung, O. Favez, C. Cuvelier, P. Thunis, S. Tsyro, R. Stern, A. Manders, R. Kranenburg, A. Aulinger, J. Bieser, M. Mircea, G. Briganti, A. Cappelletti, G. Calori, S. Finardi, C. Silibello, G. Ciarelli, S. Aksoyoglu, A. Prévôt, M.-T. Pay, J. M. Baldasano, M. García Vivanco, J. L. Garrido, I. Palomino, F. Martín, G. Pirovano, P. Roberts, L. Gonzalez, L. White, L. Menut, J.-C. Dupont, C. Carnevale, A. Pederzoli (2014). "The EURODELTA III exercise“ Model evaluation with observations issued from the 
12009 EMEP intensive period and standard measurements in Feb/Mar2009" . . MSC-W

2 Technical Report 1/2014.

3 Bessagnet, B., G. Pirovano, M. Mircea, C. Cuvelier, A. Aulinger, G. Calori, G. Ciarelli, A.

4 Manders, R. Stern, S. Tsyro, M. Garcia Vivanco, P. Thunis, M.-T. Pay, A. Colette, F.

5 Couvidat, F. Meleux, L. Rouïl, A. Ung, S. Aksoyoglu, J.-M. Baldasano, J. Bieser, G. Briganti,

6 A. Cappelletti, M. D'Isodoro, S. Finardi, R. Kranenburg, C. Silibello, C. Carnevale, W. Aas,

7 J.-C. Dupont, H. Fagerli, L. Gonzalez, L. Menut, A. S. H. Prévôt, P. Roberts, and L. White

8 (2016). Presentation of the EURODELTA III inter-comparison exercise - Evaluation of the

9 chemistry transport models performance on criteria pollutants and joint analysis with

10 meteorology. Atmos. Chem. Phys., 16, 12667-12701, 2016

11 http://www.atmos-chem-phys.net/16/12667/2016/ doi:10.5194/acp-16-12667-2016

12 Binkowski, F. and Shankar, U. (1995) The Regional Particulate Matter Model .1. Model

13 description and preliminary results, J. Geophys. Res., 100, 26191-26209.

14 Bouwman, A. F., D. S. Lee, W. A. H. Asman, F. J. Dentener, K. W. van der Hoek, and J. G. J.

15 Olivier (1997), A global high-resolution emission inventory for ammonia, Global 16 Biogeochem. Cycles, 11, 561-587.

17 Bouwman, A.F., van Vuuren, D.P., Derwent, R.G., Posch, M. (2002) A global analysis of 18 acidification and eutrophication of terrestrial ecosystems. Water, Air, and Soil Pollution 141, $19 \quad 349-382$.

20

21

22

23

Carter W.P.L. (2000) Documentation of the SAPRC-99 Chemical Mechanism for VOC Reactivity Assessment. Final Report to California Air Resources Board, Contract 92-329 and 95-308, SAPRC, University of California, Riverside,CA.

Dentener, F., Drevet, J., Lamarque, J. F., Bey, I., Eickhout, B., Fiore, A. M., Hauglustaine, D., Horowitz, L. W., Krol, M., Kulshrestha, U. C., Lawrence, M., Galy-Lacaux, C., Rast, S., Shindell, D., Stevenson, D., Van Noije, T., Atherton, C., Bell, N., Bergman, D., Butler, T., Cofala, J., Collins, B., Doherty, R., Ellingsen, K., Galloway, J., Gauss, M., Montanaro, V.,Muller, J. F., Pitari, G., Rodriguez, J., Sanderson, M., Solmon, F., Strahan, S., Schultz, M., Sudo, K., Szopa, S., and Wild, O. (2006): Nitrogen and sulfur deposition on regional and global scales: a multimodel evaluation, Global Biogeochem. Cy., 20, GB4003, doi:10.1029/2005GB002672,. 
1 EMEP (2003) Transboundary acidification, eutrophication and ground level ozone in Europe.

2 EMEP Status Report 2003, Norwegian Meteorological Institute, August 2003.

3 Erisman, J., Vermetten, A.W., Asman, W.A., Waijers-Ijpelaan, A., Slanina, J., (1988).

4 Vertical distribution of gases and aerosols: The behaviour of ammonia and related

5 components in the lower atmosphere. Atmospheric Environment 22(6), 1153-1160.

6 Flechard, C. R., Nemitz, E., Smith, R. I., Fowler, D., Vermeulen, A. T., Bleeker, A., ...\&

7 Sutton, M. A. (2011). Dry deposition of reactive nitrogen to European ecosystems: a

8 comparison of inferential models across the NitroEurope network. Atmospheric Chemistry

9 and Physics, 11(6), 2703-2728.

10 Fountoukis, C. and A. Nenes, (2007). ISORROPIA II: a computationally efficient 11 thermodynamic equilibrium model for $\mathrm{K}+-\mathrm{Ca} 2+-\mathrm{Mg} 2+-\mathrm{NH}+4-\mathrm{Na}+-\mathrm{SO} 2-4-\mathrm{NO}-3-$ $12 \mathrm{Cl}--\mathrm{H} 2 \mathrm{O}$ aerosols . Atmos. Chem. Phys., 7, 4639-4659, 2007

13 Garcia-Gomez H, Garrido JL, Vivanco MG, Lassaletta L, Rabago I, Avila A, Tsyro S, 14 Sanchez G, Gonzales Ortiz A, Gonzalez-Fernandez I, Alonso R (2014). Nitrogen deposition 15 in Spain: Modeled patterns and threatened habitats within the Natura 2000 network. Science 16 of the Total Environment.2014;485-486:450-460

17 Gauss, M., S. Tsyro, A. C. Benedictow, A.G. Hjellbrekke and S. Solberg. EMEP/MSC-W 18 model performance for acidifying and eutrophying components, photo-oxidants and 19 particulate matter in 2013. Supplementary material to EMEP Status Report 1/2015available online at www.emep.int, The Norwegian Meteorological Institute, Oslo, Norway.

Heij G. J. and T. Schneider (1991). Acidification research in The Netherlands. Elsevier Science Publishers, Amsterdam, 1991, 772 pp. ISBN 0-444-88831-4 Inness, A., Baier, F., Benedetti, A., Bouarar, I., Chabrillat, S., Clark, H., Clerbaux, C., Coheur, P., Engelen, R. J., Errera, Q., Flemming, J., George, M., Granier, C., Hadji-Lazaro, J., Huijnen, V., Hurtmans, D., Jones, L., Kaiser, J. W., Kapsomenakis, J., Lefever, K., Leitão, J., Razinger, M., Richter, A., Schultz, M. G., Simmons, A. J., Suttie, M., Stein, O., Thépaut, J.-N., Thouret, V., Vrekoussis, M., Zerefos, C., and the MACC team (2013) The MACC 28 reanalysis: an 8 yr data set of atmospheric composition, Atmos. Chem. Phys., 13, 4073-4109, 29 doi:10.5194/acp-13-4073-2013. 
1 Kuenen, J., H. Denier van der Gon, A. Visschedijk, H. van der Burgh, R. van Gijlswijk (2011)

2 MACC European emission inventory 2003-2007, TNO report, TNO-060-UT-2011-00588.

3 Lamarque, J. F., Kiehl, J. T., Brasseur, G. P., Butler, T., Cameron-Smith, P., Collins, W. D.,

4 Collins, W. J., Granier, C., Hauglustaine, D., Hess, P. G., Holland, E. A., Horowitz, L.,

5 Lawrence, M. G., McKenna, D., Merilees, P., Prather, M. J., Rasch, P. J., Rotman, D.,

6 Shindell, D., and Thornton, P., (2005): Assessing future nitrogen deposition and carbon cycle

7 feedback using a multimodel approach: analysis of nitrogen deposition, J. Geophys. Res., 110,

8 D19303, doi:10.1029/2005JD005825.

9 Lamarque, J.-F., F. Dentener, J. McConnell, C.-U. Ro, M. Shaw, R. Vet, D. Bergmann, P. 10 Cameron-Smith, R. Doherty, G. Faluvegi, S.J. Ghan, B. Josse, Y.H. Lee, I.A. MacKenzie, D.

11 Plummer, D.T. Shindell, D.S. Stevenson, S. Strode, and G. Zeng, (2013): Multi-model mean

12 nitrogen and sulfur deposition from the Atmospheric Chemistry and Climate Model

13 Intercomparison Project (ACCMIP): Evaluation historical and projected changes. Atmos.

14 Chem. Phys., 13, 7997-8018, doi:10.5194/acp-13-7997-2013.

15 Lattuati, M.: Contribution a l'etude du bilan de l'ozone tropospherique a l'interface de 16 l'Europe et de l'Atlantique Nord: modelisation lagrangienne et mesures en altitude (1997), Phd 17 thesis, Universite P.M.Curie, Paris, France,.

18 Lee, D., I. Kohler, E. Grobler, F. Rohrer R., Sausen, L., Gallardo Klenner J., Olivier, F. 19 Dentener and A. Bouwman, (1997): Estimates of global NOx emissions and their 20 uncertainties Atmos. Environ., 31, 1735-1749, 1997.

21 Longhurst, J. W. S. (ed.), (1991). Acid Deposition: Origins, Impacts and Abatement 22 Strategies. Springer-Verlag, Berlin, p. 353.

23 Menut, L., B. Bessagnet, D. Khvorostyanov, M. Beekmann, N. Blond, A. Colette, et al. 24 CHIMERE 2013: a model for regional atmospheric composition modelling. Geosci Model 25 Dev, 6 (4) (2013), pp. 981-1028

26 Nenes, A, Spyros N., C.Pilinis . ISORROPIA: A New Thermodynamic Equilibrium Model 27 for Multiphase Multicomponent Inorganic Aerosols (1998). Aquatic Geochemistry. March 28 1998, Volume 4, Issue 1, pp 123-152 
1 Nenes, A., Pilinis, C., and Pandis, S. N. (1999) Continued development and testing of a new

2 thermodynamic aerosol module for urban and regional air quality models, Atmos. Environ., $333,1553-1560$.

4 Nilsson, J., Grennfelt, P., Ministerråd, N., (1988). Critical Loads for Sulphur and Nitrogen:

5 Report from a Workshop Held at Skokloster, Sweden, 19-24 March, 1988. Nordic Council of

6 Ministers.

7 Ochoa, R., M, Arróniz-Crespo, M. A. Bowker, F. T. Maestre, M. Esther Pérez-Corona, 8 M. R. Theobald, M. G. Vivanco, E. Manrique (2014). Biogeochemical indicators of elevated 9 nitrogen deposition in semiarid Mediterranean ecosystems. Environmental Monitoring and Assessment September 2014, Volume 186, Issue 9, pp 5831-5842

11 Perniogotti D., Thunis, P., Cuvelier, C., Georgieva, E., Gsella, A., De Meij, A, Pirovano, G., 12 Balzarini, A., Riva, G. M., Carnevale, C., Pisoni, E., Volta, M., Bessagnet, B., Kerschbaumer, 13 A., Viaene, P., De Ridder, K., Nyiri, A., Wind, P. (2013) POMI: a model inter-comparison 14 exercise over the Po Valley, Air Qual Atmos Health, DOI 10.1007/s11869-013-0211-1.

15 Reich PB, Hobbie SE, Lee T, Ellsworth DS, West JB, Tilman D, Knops JMH, Naeem S, Trost 16 J. Nitrogen limitation constrains sustainability of ecosystem response to CO2 (2006). Nature. $17 \quad 2006 ; 440: 922-925$

18 Sauter, F. , Van der Swaluw, W, Manders-Groot, A. Wichink Kruit, R, Segers, A., Eskes, H., 19 (2012) LOTOS-EUROS v 1.8 Reference Guide, TNO report TNO-060-UT-2012-01451, 2012 20 Saxena, P., , A.B. Hudischewskyj, C. Seigneur, J.H. Seinfeld (1986). A comparative study of 21 equilibrium approaches to the chemical characterization of secondary aerosols. Atmos. Envir., 2220 (1986), pp. 1471-1483

23 Scott, B. C.: Parameterization of sulphate removal by precipitation (1979), J. Appl. Meteorol., 24 17, 11275-11389.

25 Seinfeld, J.H. and S. N. Pandis. Atmospheric Chemistry and Physics: From Air Pollution to 26 Climate Change, 2nd Edition. ISBN: 978-0-471-72018-8

27 Schaap, M., van Loon, M., ten Brink, H.M., Dentener, F.D. and Builtjes, P.J.H. (2004) 28 'Secondary inorganic aerosol simulations for Europe with special attention to nitrate', 29 Atmospheric Physical Chemistry, Vol. 4, pp. 857-874. 
1 Simpson, D., Fagerli, H., Hellsten, S., Knulst, J. C., and Westling, O. (2006): Comparison of 2 modelled and monitored deposition fluxes of sulphur and nitrogen to ICP-forest sites in 3 Europe, Biogeosciences, 3, 337-355, doi:10.5194/bg-3-337-2006.

4 Simpson, D., W. Aas, J. Bartnicki, H. Berge, A. Bleeker, C. Cuvelier, F. Dentener, T. 5 Dore, J. W. Erisman, H. Fagerli , C. Flechard, O. Hertel, H. van Jaarsveld, M. Jenkin, M. 6 Schaap , V. ShamsudheenSemeena , P. Thunis , R. Vautard and M. Vieno (2011). 7 Atmospheric transport and deposition of reactive nitrogen in Europe. Chapter 14 in: "The 8 European Nitrogen Assessment". Cambridge University Press. The Edinburgh Building, 9 Cambridge CB2 8RU, UK, 2011; 296-316

Simpson, D.; Benedictow, A.; Berge, H.; Bergstrom, R.; Emberson, L. D.; Fagerli, H.; Flechard, C. R.; Hayman, G. D.; Gauss, M.; Jonson, J. E.; Jenkin, M. E.; Nyiri, A.; Richter, C.; Semeena, V. S.; Tsyro, S.; Tuovinen, J. P.; Valdebenito, A.; Wind, P., (2012). The EMEP 13 MSC-W chemical transport model - technical description. Atmos. Chem. Phys. 2012, 12 (16), $14 \quad 7825-7865$.

Solazzo, E. Roberto Bianconi, Guido Pirovano, Volker Matthias, Robert Vautard, Michael D.

16 Moran, K. Wyat Appel, Bertrand Bessagnet, Jørgen Brandt, Jesper H. Christensen, Charles 17 Chemel, Isabelle Coll, Joana Ferreira, Renate Forkel, Xavier V. Francis, Georg Grell, Paola Grossi, Ayoe B. Hansen, Ana Isabel Miranda, Uarporn Nopmongcol, Marje Prank, Karine N. Sartelet, Martijn Schaap, Jeremy D. Silver, Ranjeet S. Sokhi, Julius Vira, Johannes Werhahn, Ralf Wolke, Greg Yarwood, Junhua Zhang, S. Trivikrama Rao, Stefano Galmarini, Operational model evaluation for particulate matter in Europe and North America in the context of AQMEII, Atmospheric Environment, Volume 53, June 2012, Pages 75-92, ISSN 1352-2310, http://dx.doi.org/10.1016/j.atmosenv.2012.02.045.

24 Stevens C, Dise NB, Mountford JO, Gowing DJ. Impact of nitrogen deposition on the species 25 richness of grasslands.Science. 2004; 303: 1876-1879

26 Sutton, M. A., Howard, C., Erisman, J. W., Billen, G., Bleeker, A., Grennfelt, P., van 27 Grinsven, H., and Grizzetti, B.(2011): The European Nitrogen Assessment, Cambridge 28 University Press, 612 pp.

Van Loon, M., R. Vautard, M. Schaap, R. Bergström, B. Bessagnet, J. Brandt, P.J.H. Builtjes, J. H. Christensen, C. Cuvelier, A. Graf, J.E. Jonson, M. Krol, J. Langner, P. Roberts, L. Rouil, 31 R. Stern, L. Tarrasón, P. Thunis, E. Vignati, L. White, P. Wind (2007) Evaluation of long- 
1 term ozone simulations from seven regional air quality models and their ensemble average.

2 Atmos. Environ., 41, 2083-2097.

3 Vautard, R.; Moran,M.D.; Solazzo,E.; Gilliam, R.C.; Matthias, V.; Bianconi, R.; Chemel, C.;

4 Ferreira, J.; Geyer, B.; Hansen, A.B.; Jericevic, A.; Prank, M.; Segers, A.; Silver, J.D.;

5 Werhahn, J.; Wolke, R.; Rao, S.T.; Galmarini, S. (2012). Evaluation of the meteorological

6 forcing used for the Air Quality Model Evaluation International Initiative (AQMEII) air

7 quality simulations; Atmos. Environ. 2012, 53, 15 $\square 37$

8 Vautard R., M. Schaap, R. Bergström, B. Bessagnet, J. Brandt, P.J.H. Builtjes, J.H.

9 Christensen, C. Cuvelier, V. Foltescu, A. Graff, A. Kerschbaumer, M. Krol, P. Roberts, L.

10 Rouill, R. Stern, L. Tarrason, P. Thunis, E. Vignati, P. Wind (2009) Skill and uncertainty of a

11 regional air quality model ensemble, Atmos. Environ., Volume 43, Issue 31, Pages 4822-4832,

12 ISSN $1352-2310,10.1016 /$ j.atmosenv.2008.09.083.

13 Venkatram, A. and Pleim, J. (1999) The electrical analogy does not apply to modelling dry

14 deposition of particles, Atmos. Environ., 33, 3075-3076.

15 Vestreng, V. , G. Myhre, H. Fagerli, S. Reis, and L. Tarrason (2007) Twenty-five years of 16 continuous sulphur dioxide emission reduction in Europe, Atmos. Chem. Phys., 7, 3663173681.

18 Wichink Kruit, R. J., Schaap, M., Sauter, F. J., van Zanten, M. C., and van Pul, W. A. J.: 19 Modeling the distribution of ammonia across Europe including bi-directional surface20 atmosphere exchange, Biogeosciences, 9, 5261-5277, doi:10.5194/bg-9-5261-2012, 2012. 


\section{$1 \quad$ Annexes}

\section{A.1 WET DEPOSITION SCHEMES}

\section{EMEP}

5 The EMEP model calculates in-and sub-cloud wet deposition. In-cloud wet scavenging of 6 gases and aerosols is parameterised using the precipitation rate and scavenging ratios 7 accounting for the species solubility. Below precipitating clouds, a distinction is made 8 between wet scavenging of gases and aerosols. For gases, scavenging ratios are used, whereas

9 the scavenging of aerosols is described based on size dependent collection efficiency of particles by the rain drops (assuming the raindrop fall speed of $5 \mathrm{~m} / \mathrm{s}$ and a Marshall-Palmer size distribution of rain drops).

\section{CHIM}

13 In-cloud scavenging in CHIMERE is different to that of similar models. CHIMERE takes into account the formation of "aqueous species" due to the absorption of particulate species by clouds with a kinetic of absorption. For gases, the absorption of $\mathrm{H} 2 \mathrm{O} 2$ and $\mathrm{SO} 2$ is considered, based on the equilibrium between the gas phase and the aqueous phase, which depends on $\mathrm{pH}$ following Seinfeld and Pandis (1998). Aqueous species and dissolved gases are deposited by in-cloud scavenging with a parameterization that uses a simple in-cloud scavenging coefficient. The in-cloud scavenging transfer rate $\mathrm{F}$ for particles is computed in two steps, based on the classical approach in one step (Berge, 1993): $F_{l}$ indicates the transfer of particles into droplets and $F_{2}$ indicates the scavenging of droplets in case of rain precipitation (Pernigotti et al., 2012):

$F_{1}=-\alpha w C \quad F_{2}=-\frac{P_{r}}{h w} C_{a q}$

24 Where $w$ the cloud water content $\left(\mathrm{g} \mathrm{cm}^{-3}\right), \mathrm{C}$ is the concentration of the aerosol $\left(\mathrm{g} \mathrm{cm}^{-3}\right), C_{a q}$ is the corresponding concentration in the droplet phase $\left(\mathrm{g} \mathrm{cm}^{-3}\right), \alpha$ is a transfer coefficient $\left(\mathrm{cm}^{3}\right.$

$\left.26 \mathrm{~g}^{-1} \mathrm{~s}^{-1}\right)$, Pr is the precipitation rate $\left(\mathrm{g} \mathrm{cm}^{-2} \mathrm{~s}^{-1}\right)$ and $h$ the height of the given grid box $(\mathrm{cm})$. The 27 advantage of this two steps scavenging process with transfer rates $F_{1}$ and $F_{2}$ is to lead to a 
1 droplets aerosol concentration which is considered as a loss from the aerosol side but which

2 allows for aerosol particles to reappear whenever the cloud disappears without precipitation

3 Dissolution of gases in raindrops is assumed to be irreversible in CHIMERE for both $\mathrm{HNO}_{3}$

4 and $\mathrm{NH}_{3}$. Particles are also scavenged by raindrops.

\section{CMAQ}

6 In CMAQ, pollutant scavenging is calculated by two methods, depending on whether the 7 pollutant participates in the cloud water chemistry (Byun and Schere, 2006). For those 8 pollutants that participate in the cloud chemistry, the amount of scavenging depends on the 9 Henry's law constant, dissociation constants and cloud water pH Chang et al. (1987). For pollutants that do not participate in aqueous chemistry, CMAQ uses the Henry's law equilibrium equation to calculate cloud water concentrations based on the liquid water content of the cloud. The wet deposition of a chemical species depends on the precipitation rate and

13 the cloud water concentration.

\section{CAMX}

15 The basic model implemented in CAMX uses a scavenging approach in which the local rate 16 of concentration change within or below a precipitating cloud depends on a scavenging 17 coefficient (ENVIRON, 2011). The scavenging coefficient is determined differently for gases 18 and particles based on relationships described by Seinfeld and Pandis (1998). Two 19 components are calculated for gases: direct diffusive uptake of ambient gases into falling precipitation and growth of cloud droplets containing dissolved gases. Wet scavenging of gases by precipitation occurs within and below clouds. Below the cloud, the total gas concentration in a given grid cell is available for scavenging. Within a cloudy cell the total gas concentration must first be partitioned into an aqueous fraction within cloud water and the remaining gaseous fraction within the interstitial air. Both aqueous and interstitial gases within a cloudy cell are available for scavenging, but are removed at different rates. The two components determined for particles are: impaction of ambient particles into falling precipitation with an efficiency that is dependent on particle size and growth of cloud droplets containing particle mass. Rain drops, snow flakes and graupel particles are each separately represented by a single mean size, mass and fall speed. The scavenging model in CAMX 
1 precipitation forms and that dissolved gases are in equilibrium with ambient concentrations

2 according to Henry's law.

\section{LOTO}

4 LOTOS-EUROS includes a pH-dependent cloud chemistry following the approach by 5 (Banzhaf et al 2012). In-cloud scavenging is not taken into account. Below-cloud scavenging 6 is done using scavenging coefficients for gases and particles following Scott (1979) over the 7 atmospheric column covered by the model (lower $3.5 \mathrm{~km}$ of troposphere)

\section{MINNI}

9 In MINNI, the parameterization of wet deposition follows EMEP (2003) approach and includes in-cloud and below-cloud scavenging of gas species and particles. Different scavenging ratios (in- and below-cloud) and collection efficiencies for gas-phase species and aerosols are considered. Sulphate production within clouds is also considered using Henry's law equilibrium equations for $\mathrm{SO}_{2}, \mathrm{O}_{3}$ and $\mathrm{H}_{2} \mathrm{O}_{2}$.

\section{A.1 DRY DEPOSITION SCHEMES}

EMEP

The EMEP model uses a resistance formulation for the dry deposition of gaseous species, whereas a mass-conservative equation from Venkatram and Pleim (1999) is used to calculate aerosol dry deposition. Dry deposition velocities are surface type dependent and are calculated for 16 land-use classes. The total dry deposition in a grid-cell is the area-weighted average of all ecosystem-specific depositions within the cell.

\section{CHIMERE}

24 The dry deposition process is commonly described through a resistance analogy (Wesely 25 (1989)). For each model species, three resistances are estimated; the aerodynamical 26 resistance, the resistance to diffusivity near the ground and the surface resistance. Deposition 27 occurs if the total resistance is low. For particles, the settling velocity is added. More 28 information is included in Laurent et al. (2013)

\section{CMAQ}


1 CMAQ initially included the same description for the dry deposition of aerosols, as defined

2 by Binkowski and Shankar (1995), but CMAQ versions higher than 4.5 use the approach of

3 Venkatram and Pleim (1999), where the dry deposition is parameterised following a non-

4 electrical analogy with the objective to maintain mass conservation.

5 To calculate the dry deposition velocity $\left(\mathrm{V}_{\mathrm{d}}\right)$ for aerosols, CMAQ considers aerosol size

6 distributions with three log-normal modes and computes aerosol $\mathrm{V}_{\mathrm{d}}$ as a function of particle

7 diameter and meteorological conditions for each mode for mass, surface area and number. An

8 integrated $V_{d}$ is computed for each mode by integrating these equations over each log-normal

9 size distribution. The modal-integrated $V_{d}$ is a function of modal mass mean diameter.

10 Aerosol treatment in CMAQ v. 5.0 includes a dynamically interactive coarse mode for NO3,

11 hygroscopic growth of particles and advanced treatment of secondary organic aerosols.

12 Recent reviews of air-surface exchange (Fowler et al., 2009) indicate the need to account for

13 the canopy structure and its effects on particle $\mathrm{V}_{\mathrm{d}}$. Characterizing the fine scale morphology

14 in a regional air quality model remains a challenge and will be a future focus area for model

15 development.

\section{CAMX}

17 The gas resistance model of Zhang et al. (2003) was used in the CAMX simulations. This 18 scheme uses the "leaf area index" (LAI) to scale pollutant uptake by biota and uses an 19 updated representation of non-stomatal deposition pathways. In this model, aerodynamic and 20 boundary resistances are very similar to the original Wesely (1989) formulations but the 21 surface resistance is calculated differently.

\section{MINNI}

23 MINNI implements CMAQ aerosol model "aero3" and consequently uses the same approach 24 to estimate aerosol dry deposition velocities. 
- The estimates of $\mathrm{N}$ and $\mathrm{S}$ deposition by six regional models are evaluated

- The inclusion of sea salt sulfate emissions was found to be important

- Formation of $\mathrm{NH} 3+\mathrm{NH}_{4}^{+}$is generally underestimated in summer

- There is a general underestimation of wet deposition of reduced $\mathrm{N}$ by most models

- Different performance was found for the different models and pollutants 